\title{
Additions to the British list of Megaselia Rondani (Diptera: Phoridae), including two new species, from the crowns of ancient pollarded trees
}

\author{
R.H.L. Disney ${ }^{\mathrm{a} *}$ and A. Russell-Smith ${ }^{\mathrm{b}}$ \\ ${ }^{a}$ Department of Zoology, University of Cambridge, Cambridge, UK; ${ }^{b}$ Doddington, Sittingbourne, \\ Kent, UK
}

(Received 19 November 2013; accepted 6 October 2014; first published online 20 December 2014)

\begin{abstract}
Among species trapped in the crowns of ancient pollarded trees in southern England are Megaselia russellsmithi Disney sp. n, M. velutinicavus Disney sp. $\mathrm{n}$. and $M$. henrydisneyi Durska, which is a further addition to the British List. The hitherto unknown females of $M$. henrydisneyi, M. serrata (Wood) and M. speiseri Schmitz are described. M. gargarans Schmitz and M. basiturgida Disney \& Durska are synonymised with $M$. crassipes (Wood) following recognition of an error in Schmitz's description of M. gargarans and of other confusions in the literature.
\end{abstract}

http://zoobank.org/urn:1sid:zoobank.org:pub:1CC46F9C-AB02-446C-BF834D9529508DFA

Keywords: Phoridae; new species; new synonyms; England; pollarded trees

\section{Introduction}

The Phoridae in this report were collected as by-catch from a survey conducted in 2012 for the rare and threatened spider species, Midia midas (Simon 1894). This money spider is always associated with ancient trees, and previously was recorded from only five sites in the UK.

Six sites across eight counties in southern England were surveyed (Table 1). The original land use of most sites was either as deer parks or wood pasture, although one woodland site, Wytham Wood, was also included. It was decided to standardise sampling using pitfall traps placed in rot holes or snags in the crowns of ancient pollards or other veteran trees. This decision was taken in the light of positive results from an earlier survey for saproxylic beetles conducted in Epping Forest by Imogen Wilde. Examination of the by-catch from this survey showed that $16 \%$ of all pitfall traps placed in ancient oak pollards caught Midia.

\section{Methods}

The traps used were plastic coffee beakers measuring $8 \mathrm{~cm}$ in depth and $6.5 \mathrm{~cm}$ in diameter. Each trap consisted of two beakers, nested one within the other, to reduce disturbance when being emptied and refilled. Traps were half filled with a solution of ethylene glycol diluted $50 \%$ with water, to which a small quantity of domestic detergent was added to reduce surface tension. The traps were covered with a dome of galvanised chicken wire in an attempt to reduce the amount of

*Corresponding author. Email: rhld2@hermes.cam.ac.uk 
Table 1. Sites surveyed, traditional land use and number of visits.

\begin{tabular}{lllcl}
\hline County & \multicolumn{1}{c}{ Site } & \multicolumn{1}{c}{ Land use } & Visits & Methods \\
\hline Kent & Merton Hatch & Wood pasture? & 3 & Pitfall (22) \\
Essex & Hatfield Forest & Deer park & 2 & Pitfall (19) \\
Essex & Hainault Forest & Wood pasture & 3 & Pitfall (20) \\
Berkshire & Windsor Great Park & Deer park & 3 & Pitfall (19) \\
Buckinghamshire & Burnham Beeches & Wood pasture & 3 & Pitfall (21) \\
Oxfordshire & Wytham Wood & Woodland & 2 & Pitfall (15) \\
\hline
\end{tabular}

wind-blown leaf litter and other debris entering them. They were placed in rot holes and snags in ancient trees, normally at heights ranging between 2 and $3 \mathrm{~m}$ above ground. Initially, it was planned to place a minimum of 20 traps in separate trees at each site. Because it was sometimes difficult to find suitable niches in the trees where traps could be adequately bedded into the substrate, the actual numbers varied from 15 to 22 per site (Table 1). At all sites other than Wytham Wood, traps were operated over a period of 2 months in May and June 2012, and were emptied at monthly intervals. The catch from each trap was transferred to pre-labelled tubes and preserved in 70\% ethanol. RHLD subsequently slide mounted the Phoridae in Berlese Fluid (Disney 2001).

\section{The species}

Some Megaselia females cannot be named with our present state of knowledge, especially those in Schmitz \& Beyer's (1965) Abteilung IV, Zweite Reihe. Not only are their keys almost entirely based on males, but the descriptions of the females, where known, are perfunctory to the extent that they do not allow distinction from similar species.

46 species were obtained in the traps set in the crowns of ancient pollards. The addition to the British List and one of the new species key to a cluster of species that includes the poorly described Megaselia gargarans Schmitz and the subsequently described M. basiturgida Disney \& Durska, so these are considered first.

\section{Megaselia crassipes (Wood)}

(Figures 1-3)

Phora crassipes Wood 1909, p. 24

Aphiochaeta dactylata Lundbeck 1920, p. 9. Schmitz, 1952, p. 359

Aphiochaeta exclusa Lundbeck 1921, p. 134. Schmitz, 1952, p. 361

Megaselia gargarans Schmitz 1948, p. 393, syn. n.

Megaselia basiturgida Disney and Durska 2011, p. 528, syn. n.

Megaselia crassipes was not obtained in the present study but it needs to be distinguished from a new species (described below) that was obtained, and from the addition to the British List.

The recognition of $M$. crassipes has proved troublesome from the beginning. Lundbeck (1922) only included Wood's species in his key to the species of his Group IV. However, he included his $M$. dactylata and M. exclusa in both the key and the text. Subsequently, Schmitz (1952) synonymised both these species with $M$. crassipes. The 


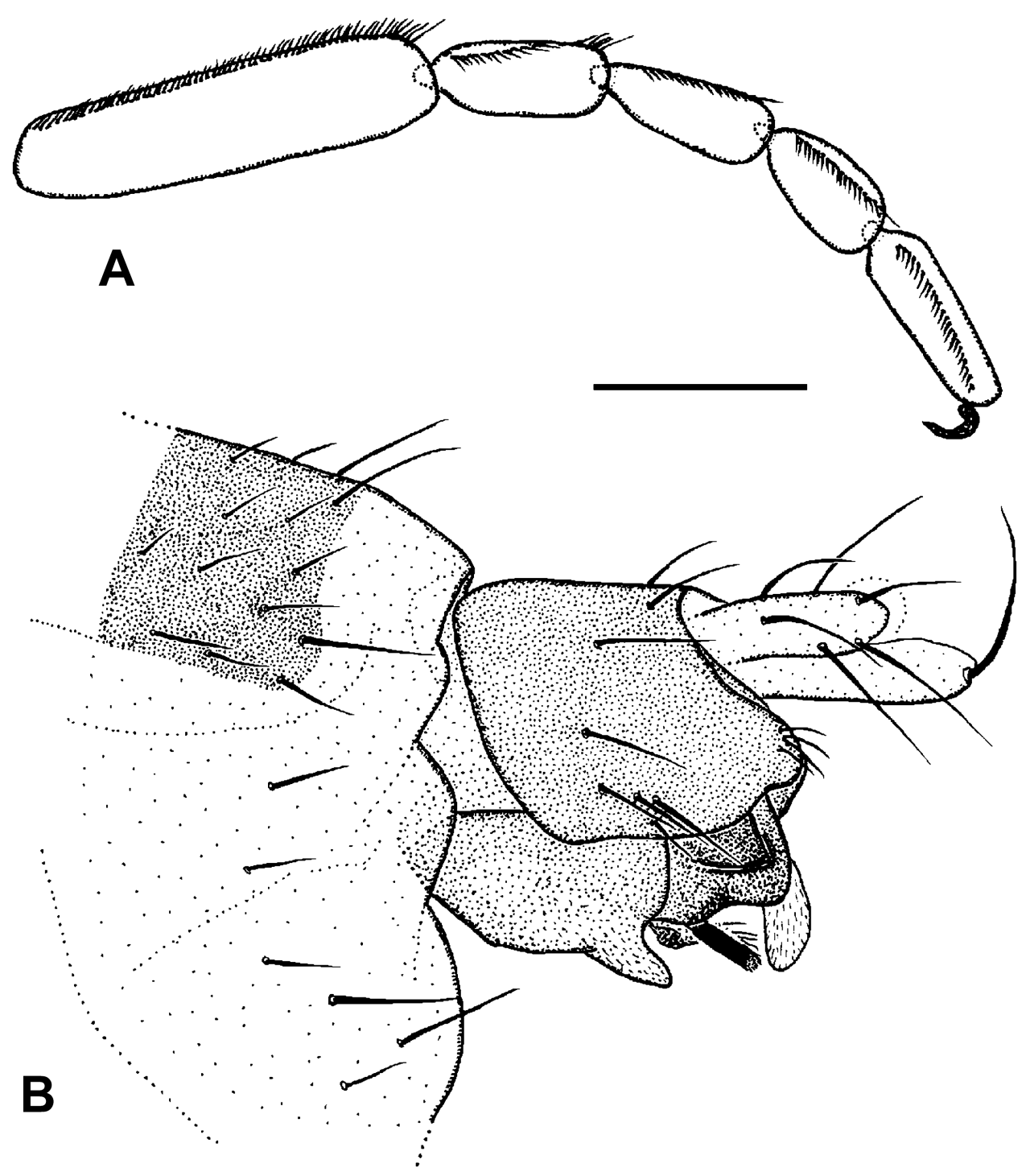

Figure 1. Megaselia crassipes male. (A) Posterior face of front tarsus; (B) left face of hypopytgium. Scale bar: $0.1 \mathrm{~mm}$.

effect of this was to play havoc with Lundbeck's key to his Group IV. For example, his first couplet separates those species with long costal cilia from those in which they are short. It is evident, however, that these cilia vary across accepted conventions regarding the boundary between 'short' and 'long'. The failure to appreciate this caused Schmitz (1958) to key out this species in his Abteilung IV, Erste Reuhe. Schmitz and Beyer (1965) then keyed out $M$. gargarans in Abteilung IV, Zweite Reihe. To add to the confusion, Borgmeier (1968) cited the wrong paper of Schmitz for the synonymy of $M$. dactylata, but correctly observed that Schmitz (1958) had erroneously referred a photo of the wing of another species to $M$. crassipes. 

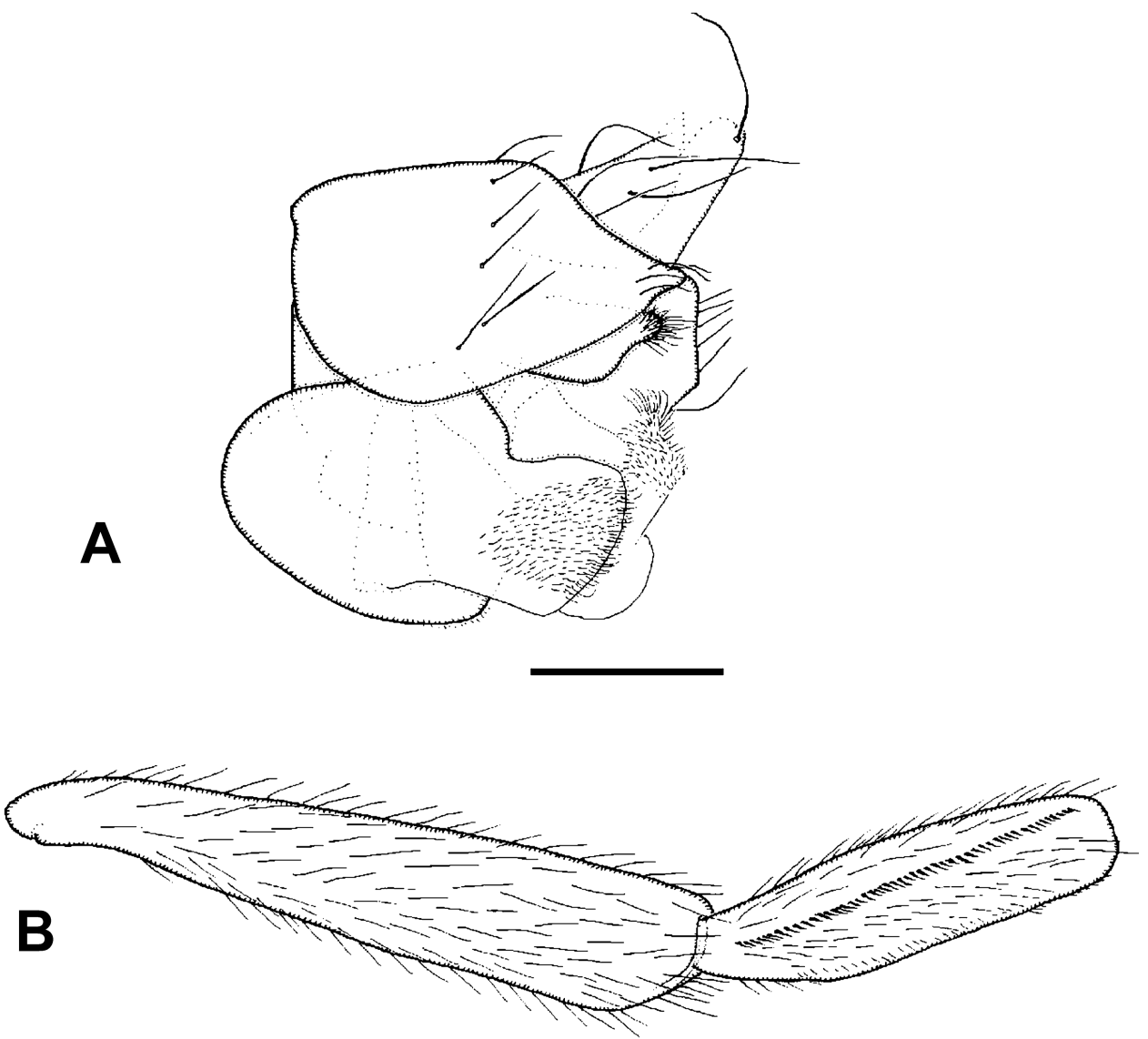

Figure 2. Megaselia crassipes male (synonym of M. basiturgida). (A) Left face of hypopygium; (B) posterior face of front tibia and basitarsus. Scale bar: $0.1 \mathrm{~mm}$.

The recognition of $M$. gargarans has also proved troublesome. In the keys to the males of the species of the British Isles (Disney 1989), it seemingly runs to couplet 81, lead 2 , to $M$. crassipes. Schmitz did not provide a figure of the hypopygium but described the anal tube as being 'kurz, kaum länger als hoch', which would immediately exclude $M$. crassipes. In the keys of Schmitz and Beyer (1965), the males of M. gargarans run to couplet 52 on p. 523. Furthermore, in the text Beyer pointed out that Schmitz's description of the anal tube was incorrect, as he reported his measurement of its length-tobreadth ratio as being 8:4. Examination of Schmitz's slide mount of a paratype male of M. gargarans (in the Museum Koenig, Bonn) endorses this (Figure 3). Furthermore, it is evident that it is a specimen of $M$. crassipes at the larger and darker end of the spectrum of variation in this species. Therefore, the synonymy of $M$. gargarans with $M$. crassipes is herewith formally proposed. $M$. basiturgida was described from two similarly darker males, but which are not quite as large as the paratype of $M$. gargarans. Furthermore, the left hypandrial lobes of these two males are paler than usual. However, in every other respect, they lie within the ranges of variation for $M$. crassipes. Therefore, the synonymy of $M$. basiturgida with $M$. crassipes is also herewith formally proposed. Critical details of 


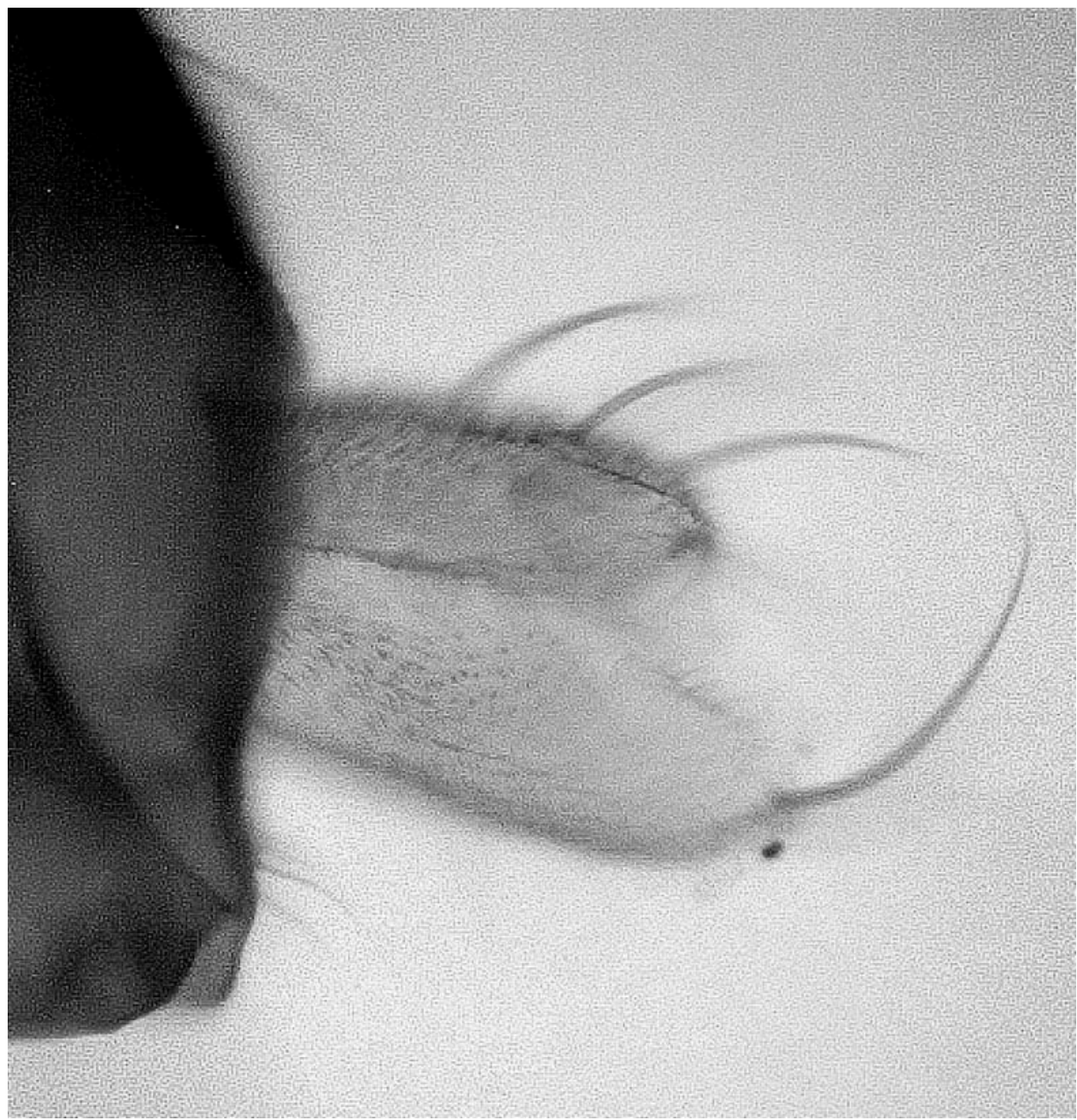

Figure 3. Megaselia crassipes male (synonym of M. gargarans), left face of anal tube.

M. crassipes are given in Figures 1-2 and its recognition clarified in the revised couplets 79-81 of the key to the males recorded from the British Isles (Disney 1989) (see below).

\section{Megaselia henrydisneyi Durska}

(Figures 4-6)

Megaselia henrydisneyi Durska, in Disney and Durska 1998, p. 437 (male)

The recognition of this species was initially impeded by the badly faded condition of the type series from Poland when compared with the fresh material from England, and by two errors in the original description. The latter included it being abdominal tergite 6 , as opposed to $\mathrm{T} 2$ being longer than the rest of the abdominal tergites, and a pair of prescutellar dorsocentral bristles being present 

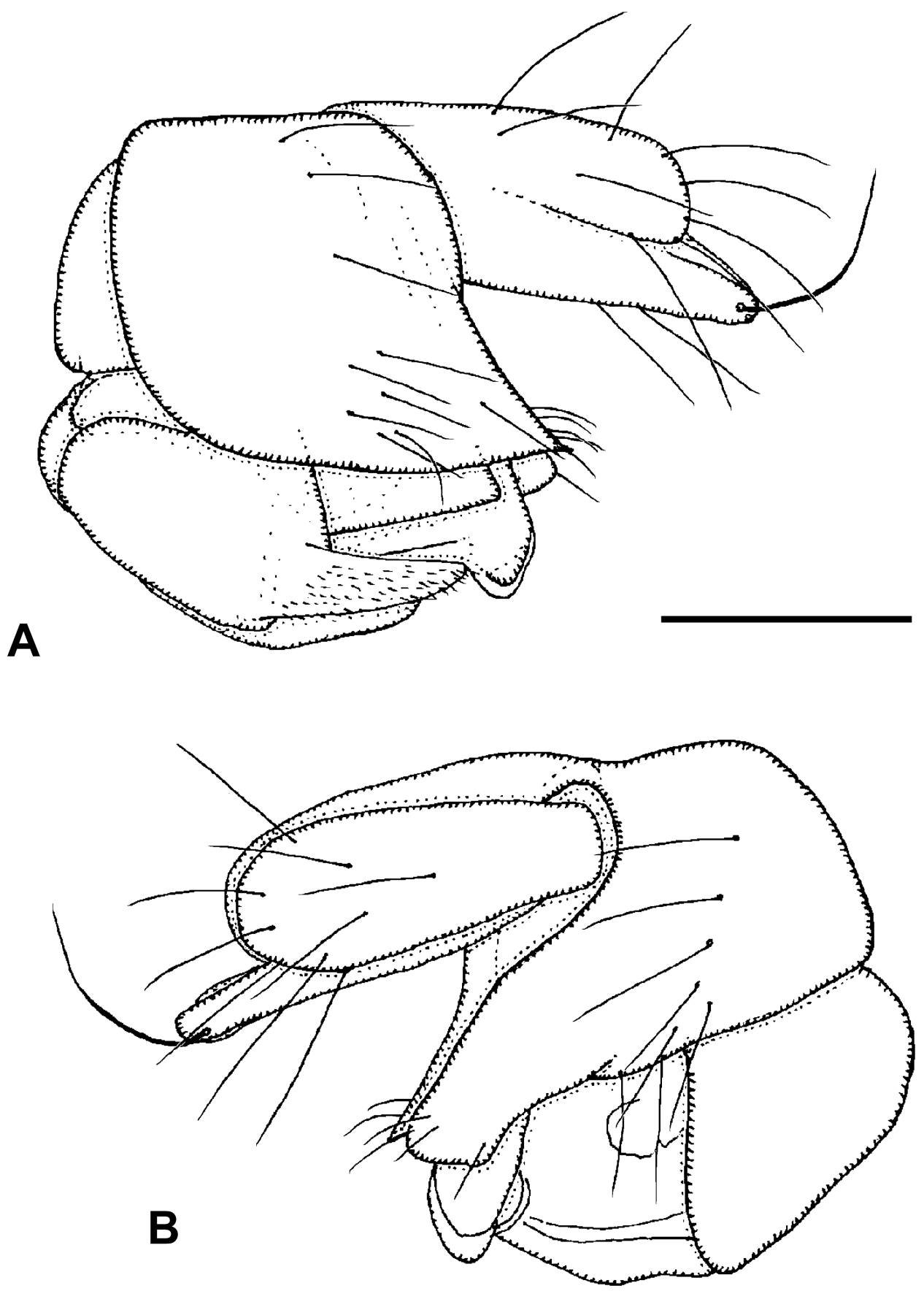

Figure 4. Megaselia henrydisneyi male, hypopygium. (A) Left face; (B) right face. Scale bar: $0.1 \mathrm{~mm}$. 

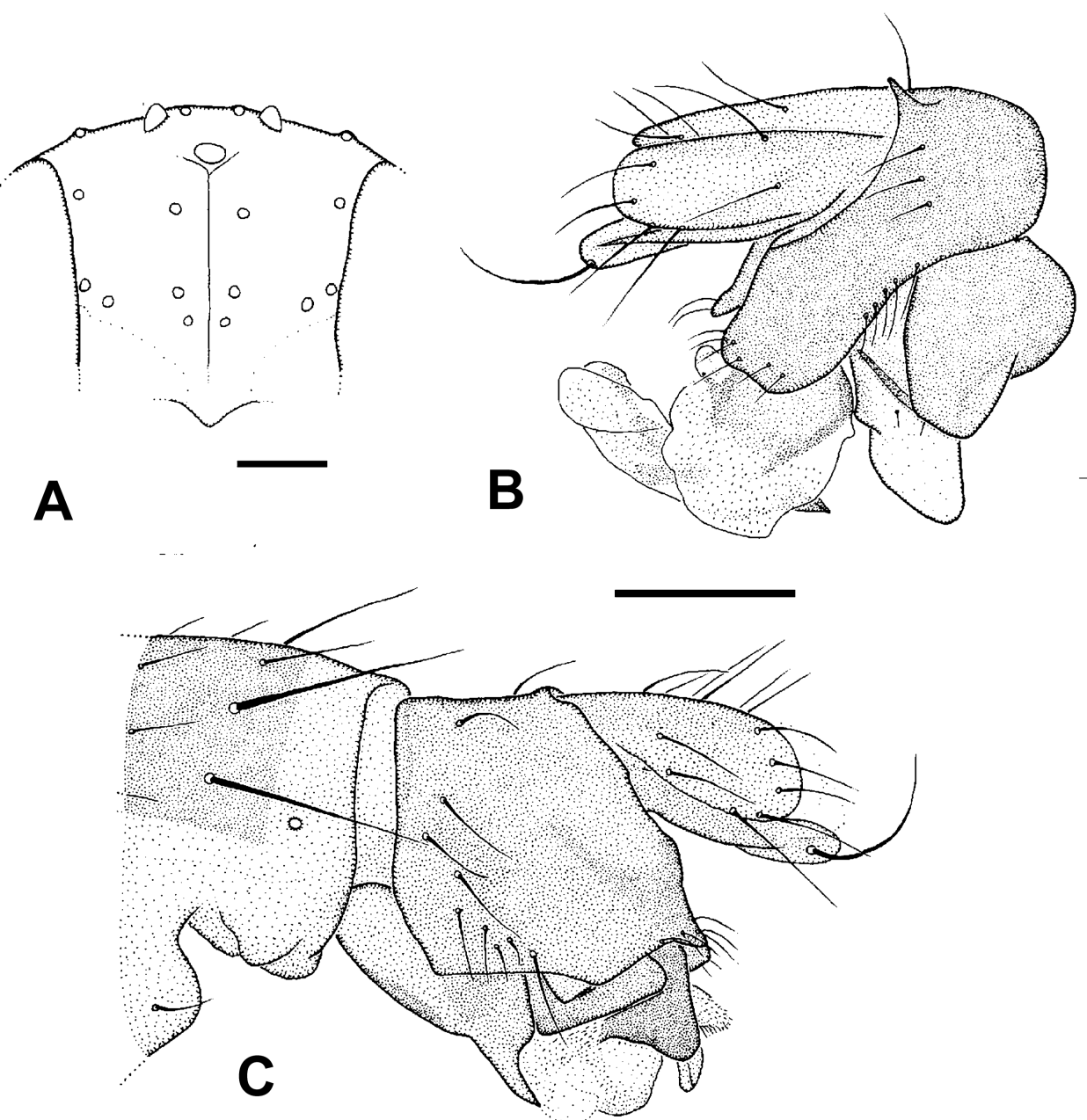

Figure 5. Megaselia henrydisneyi male. (A) Frons (with bristles represented by their basal sockets only); (B) right face of hypopygium; (C) left face of hypopygium. Scale bars: $0.1 \mathrm{~mm}$.

rather than absent. In some specimens these bristles are indeed lost, but their basal sockets are present. Critical details of the male are given in Figures 4-5. The hitherto unknown female is described below.

\section{Female}

Head similar to male except labrum is about 1.4 times wider than diameter of postpedicel and the palp about $0.4-0.5$ times as wide but 1.8 times as long as the latter. Labella paler, with submarginal pale greyish bands above and very few bristles reduced to small spinules below. Otherwise head similar to male. Thorax as male. Abdominal tergites brown. T5-T7 as Figure 6C. Venter grey, and with hairs below segments 3-6. Sternite 7 a narrow triangle, but of irregular outline, with 


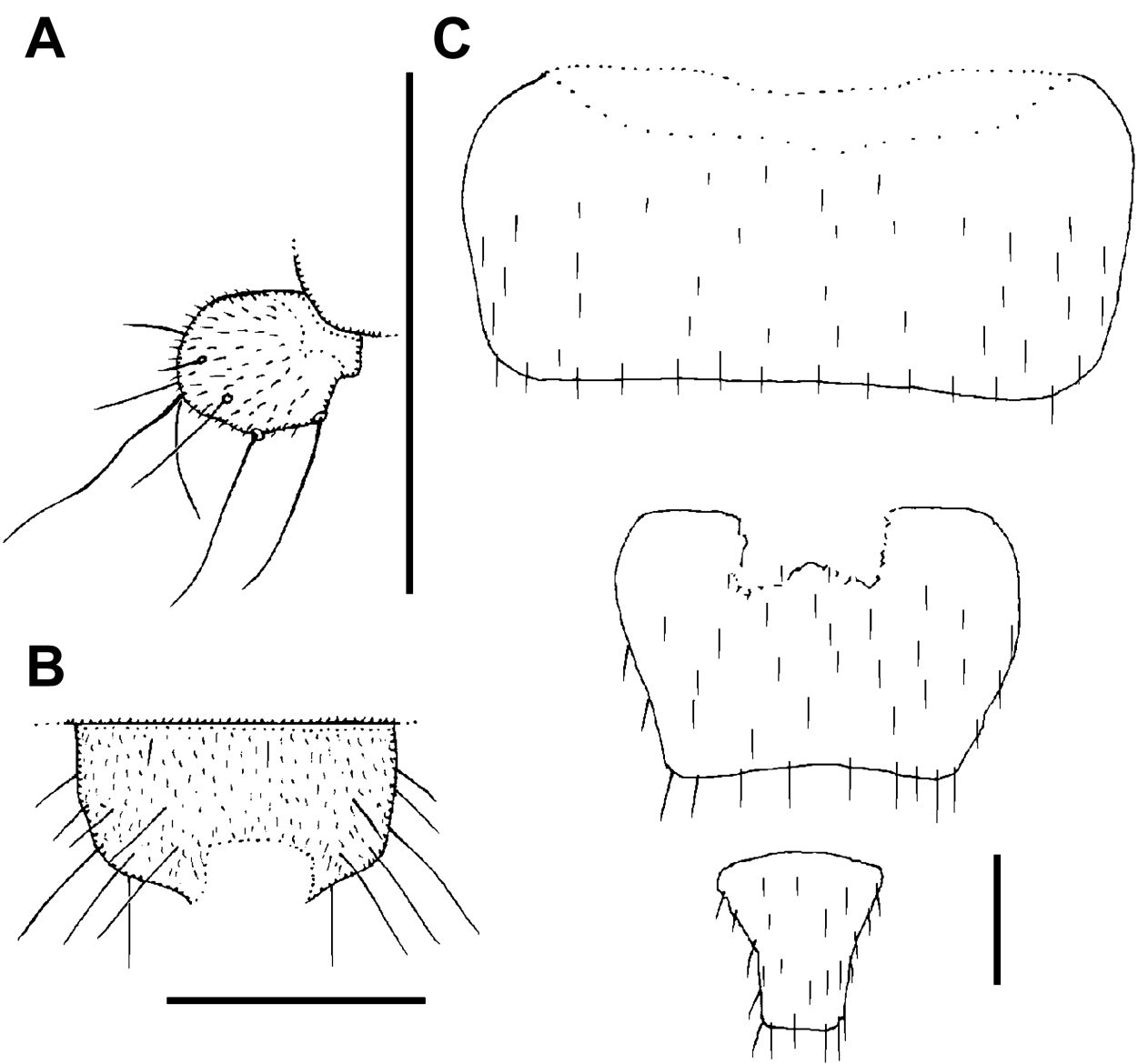

Figure 6. Megaselia henrydisneyi female, details of abdomen. (A) Left cercus; (B) lobes at rear of sternum 8; (C) tergites 5-7. Scale bars: $0.1 \mathrm{~mm}$.

five to 10 hairs. Posterolateral lobes at rear of sternum 8 as Figure 6B. Cerci lightly tinged brown and as Figure 6A. Furca not evident. Dufour's crop mechanism about twice as long as greatest width and rounded behind. Legs similar to male but the front tarsus is more slender and about 1.5 times as long as that of the male. Wing as male except $1.87-2.14 \mathrm{~mm}$ long. Costal index 0.49-0.50. Costal ratios 2.83.6:1.6-2.0:1. Costal cilia $0.14-0.16 \mathrm{~mm}$ long. With five axillary bristles. Otherwise it and haltere as male.

One female was gravid with 40 eggs that measure $0.32 \mathrm{~mm}$ long and $0.13-0.14 \mathrm{~mm}$ wide.

\section{Material}

Obtained in pitfall traps in crowns of old pollards at the following localities. Berkshire, Windsor Great Park, (grid ref. SU9872), Bear Rails, crowns of old oaks (Quercus spp.), 22.vi-13.vii.2012; Buckinghamshire, Burnham Beeches, 2-31. 
v.2012; Essex, Hatfield Forest (grid ref. TL5319), 22.v-15.vi.2012; Kent, Merton Hatch, Bockhanger Wood, hornbeam (Carpinus betulus), 14.v.-9.vi.2012.

\section{Recognition}

In the keys to the males of British species (Disney 1989), the males run to couplets 79 81 , which are revised below.

Megaselia russellsmithi Disney sp. $\mathrm{n}$.

(Figures 7-8)

\section{Male}

Frons brown, clearly broader than long, with 48-64 hairs and dense but very fine microtrichia. Upper supra-antennal bristles (SAs) almost as long and robust as the lower pair. The antials about level on frons with upper SAs but a little lower than anterolaterals, and about twice as far from upper SAs as either is from an anterolateral bristle. Pre-ocellars a little further apart than either is from a mediolateral bristle, which is slightly higher on frons. Cheek with three to six bristles and jowl with three that are longer and more robust. The subglobose postpedicels are brown, without subcutaneous pit sensilla (SPS) vesicles. Palps yellow, at most a third as broad as postpedicel but 1.5 times as long as breadth of latter, with five to six bristles (the longest shorter than lower SAs but longer than those on jowl) and six to eight hairs. Labrum pale grey and about 0.9 times as wide as a postpedicel. Labella paler, the dorsolateral bands being scarcely differentiated, and with very few short spinules below. Thorax brown. Three notopleural bristles and no cleft in front of these. Mesopleuron with five to 11 (mean: 7) hairs. Scutellum with an anterior pair of hairs (subequal to those in middle of scutum) and a posterior pair of bristles. Abdominal tergites brown with small hairs, but those at rear of T6 longer. Venter grey, and with hairs on segments 3-6, but those on 3 and 4 are few and may be reduced or absent. Hypopygium mainly brown but the left lobe of hypanduum and anal tube are pale grey, and as in Figures 7A-B. Apart from brown patch on mid coxa, legs yellowish brown or paler, the hind femur

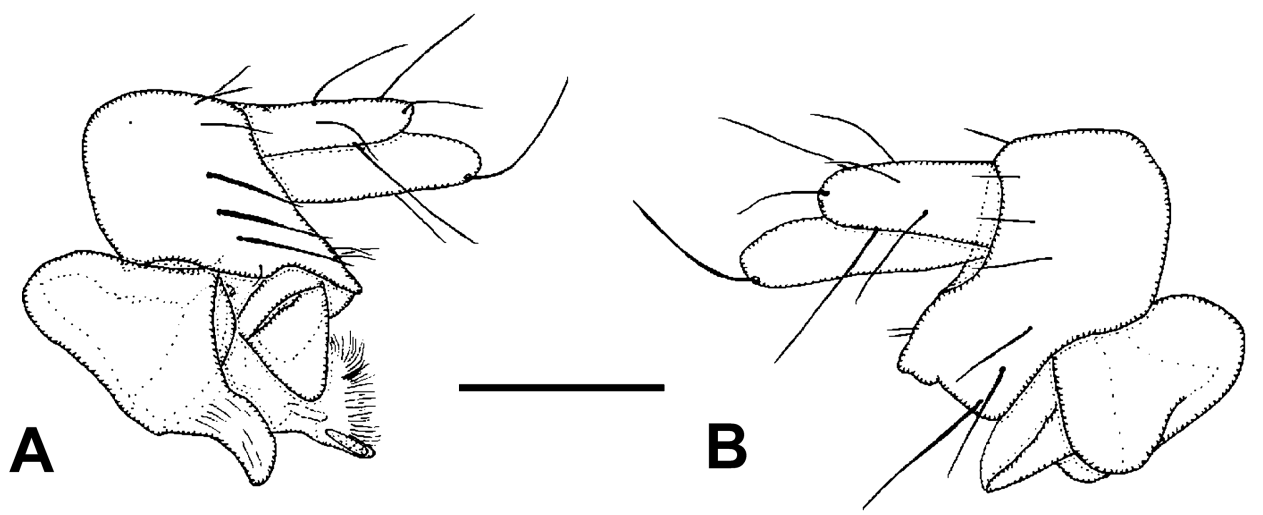

Figure 7. Megaselia russellsmithi male, hypopygium. (A) Left face; (B) right face (minus penis complex). Scale bar: $0.1 \mathrm{~mm}$. 

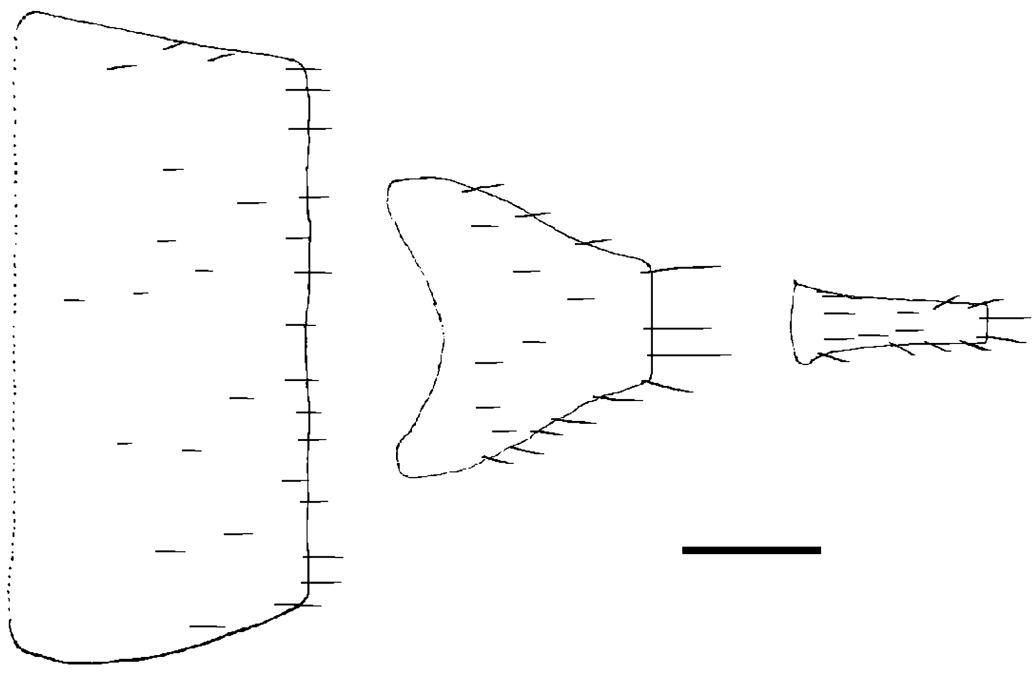

A
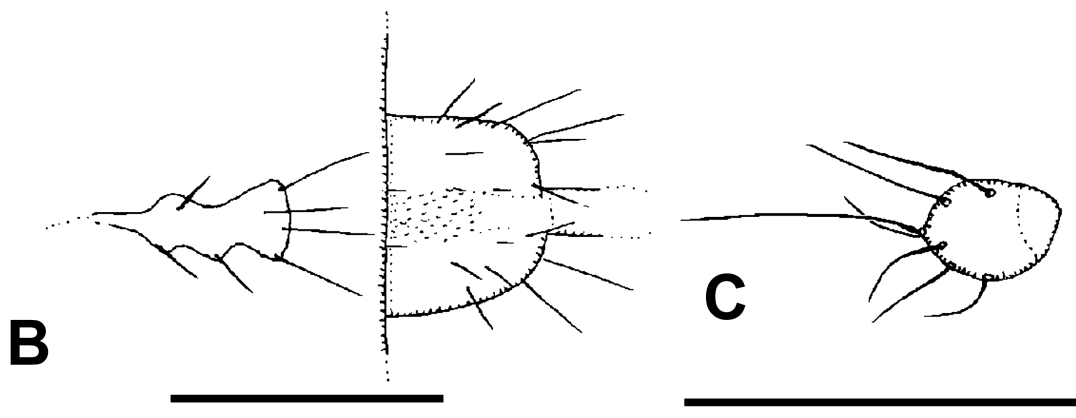

Figure 8. Megaselia russellsmithi female, details of abdomen. (A) Tergites 5-7; (B) sternite 7 and lobes at rear of sternum 8; (C) right cercus. Scale bars: $0.1 \mathrm{~mm}$.

being darkest with the tip darker still. Fore tarsus with posterodorsal hair palisade on segments $1-4$ or 5 and 5 clearly longer than 4 . Its basitarsus with one to two rows of hairs modified as short spinules. Dorsal hair palisade of mid tibia extends about 0.6 times its length. Hairs below basal half of hind femur shorter than those of anteroventral row of outer half. Hind tibia with 17-21 differentiated posterodorsal hairs and spinules of apical combs simple. Wings $1.3-1.6 \mathrm{~mm}$ long. Costal index 0.46-0.49. Costal ratios 2.5-3.2:1.11.3:1. Costal cilia (of section 3) $0.07-0.08 \mathrm{~mm}$ long. Hair at base of vein 3 minute or absent. With two axillary bristles (one with three on one wing only), both being longer than costal cilia. Subcosta $(\mathrm{Sc})$ not reaching R1. Thick veins and veins 4-6 pale greyish brown, vein 7 very pale grey. Membrane tinged grey (evident to naked eye when viewed against a white background). Haltere brown.

\section{Female}

Head similar to male but labrum about 1.3 times wider than diameter of postpedicel and palp about 1.3 times as long as latter's diameter. Otherwise head similar to male. 
Thorax as male. Abdominal tergites brown. T5-T7 as in Figure 8A. Venter grey, and with hairs below segments 4-6 or 5-6 only. Sternite 7 and posterolateral lobes at rear of sternum 8 as in Figure 8B. Cerci grey and as in Figure 8C. Furca not evident. Dufour's crop mechanism about twice as long as greatest width, rounded behind and about 0.10 $0.11 \mathrm{~mm}$ long. Legs similar to male but 21-23 differentiated posterodorsal on mid tibia. Wing as male except $1.7-1.8 \mathrm{~mm}$ long. Costal index 0.48-0.50. Costal ratios 2.6 3.2:1.1-1.2:1. Costal cilia $0.10-0.12 \mathrm{~mm}$ long. Otherwise it and haltere as male.

\section{Material}

Holotype: male, England, Berkshire, Windsor Great Park, (grid ref. SU9872), Bear Rails, crown of old oak (Quercus sp.) pollard, pitfall trap, 22.vi-13.vii.2012, A. R-S, (UCMZ, 20-172). Paratypes: two males, two females as holotype (20-172 \& 173).

\section{Etymology}

Named for the collector Dr. Tony Russell-Smith.

\section{Recognition}

In the keys to the males of British species (Disney 1989), the males run to couplets 7981 , which are revised below.

\section{Megaselia serrata (Wood)}

(Figures 9-17)

Phora serrata Wood 1910, p. 150 (male)

The male of this species is covered by the key to British species (Disney 1989). The hitherto-unknown female is described below.

\section{Female}

Head similar to male but the greyish-brown labrum is 1.1-1.2 times as wide as the diameter of the postpedicel (which, like that of the male, lacks subcutaneous pit sensilla [SPS] vesicles). In the male, the labrum is only about 0.08 times as wide as a postpedicel. Labella paler, with submarginal light brown bands above and very few bristles reduced to small spinules below at tips. Otherwise head similar to male. Thorax similar to male, in having three bristles on notopleuron, seven to 10 hairs on mesopleuron, and scutellum with an anterior pair of small hairs and a posterior pair of bristles. Abdominal tergites brown and as in Figures 9 and 10. Terminal segments as in Figure 12. Venter grey, and with hairs below segments 3-6. Sternite 7 brown and as in Figure 12. Posterolateral lobes at rear of sternum 8 tinged brown and with three hairs at rear margin and several smaller ones further forward (Figure 13). Cerci brown and as in Figure 11. Furca pale grey and outline variable in relation to angle of view (Figures 14-16). Dufour's crop mechanism seemingly absent. Legs similar to male but the hind femur lacks the hooked spines beneath the basal half, where 


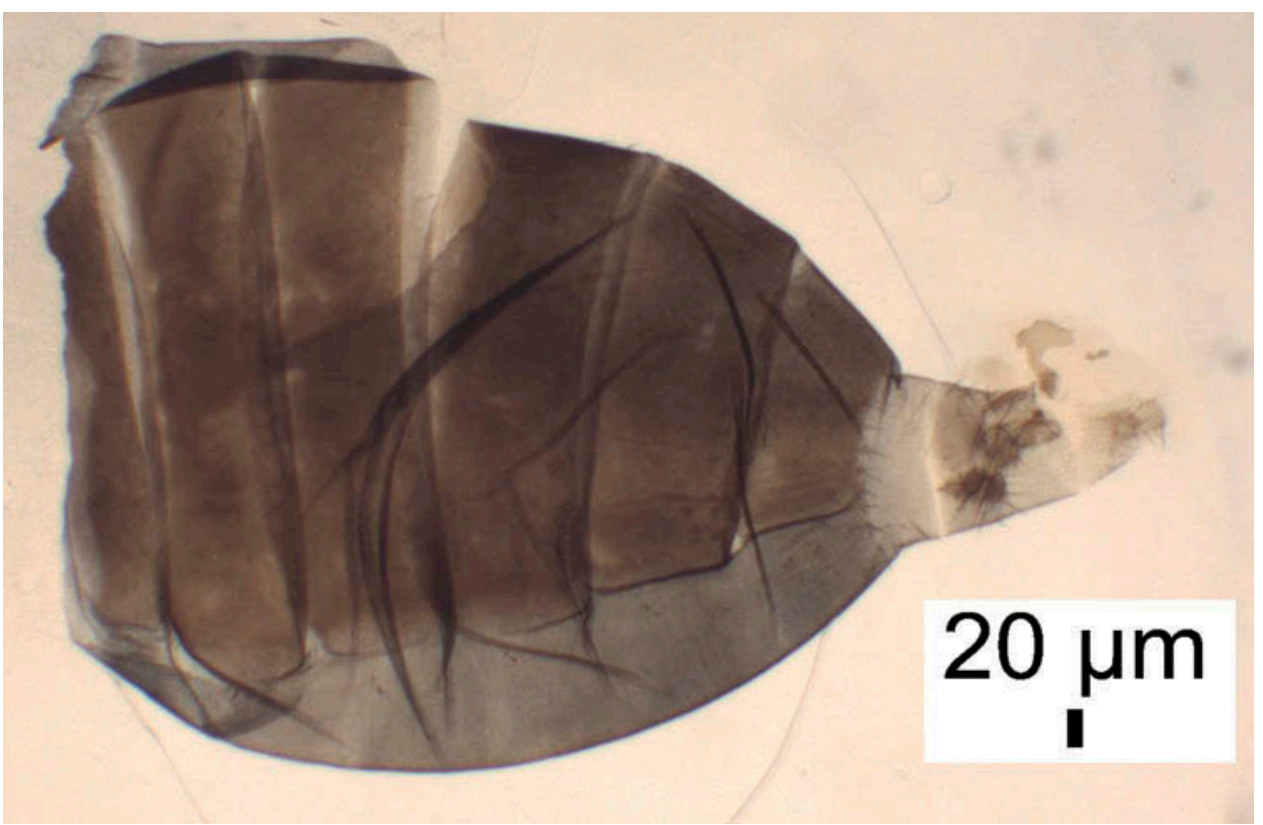

Figure 9. Megaselia serrata female, details of abdomen, tergites.

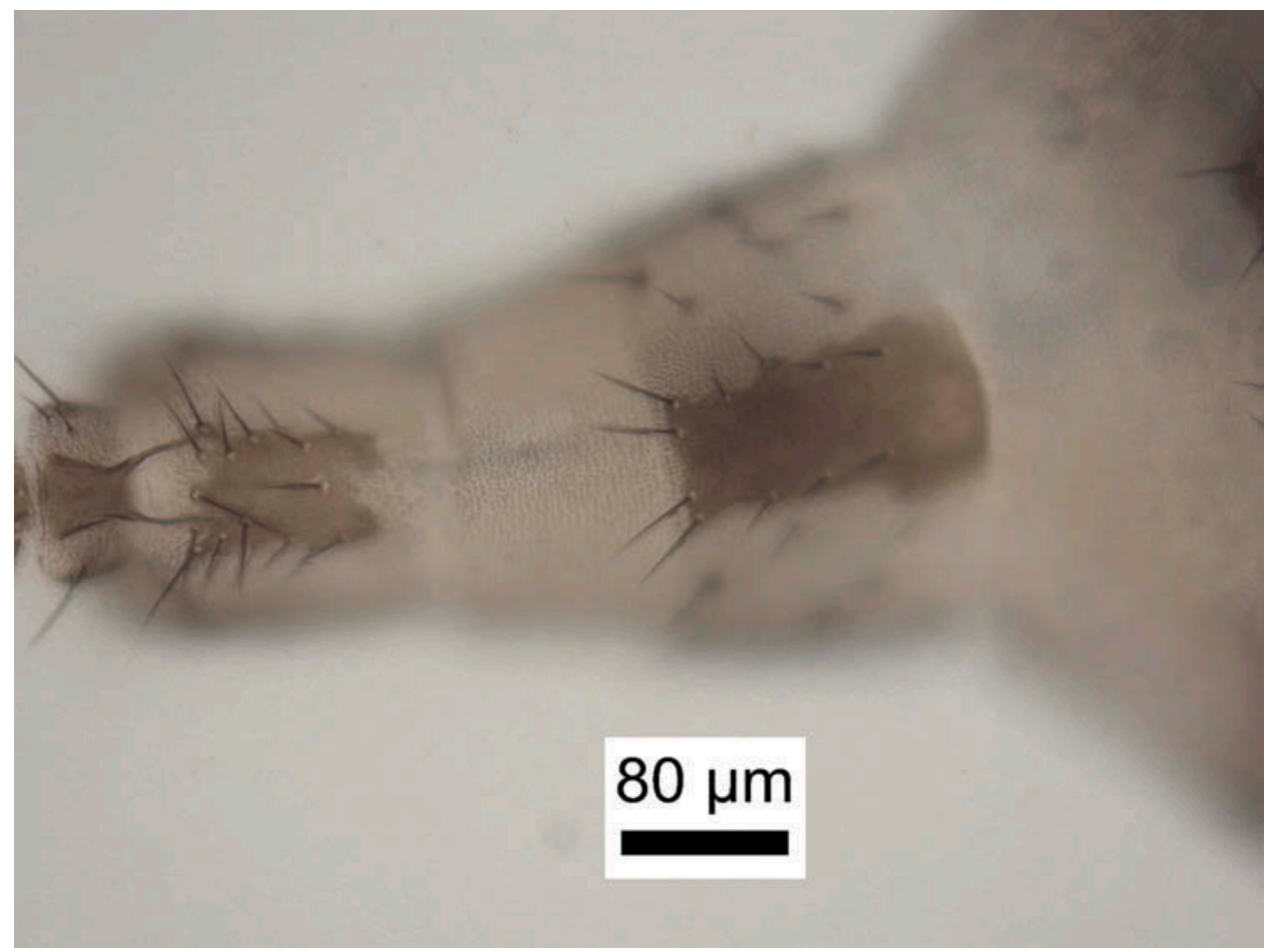

Figure 10. Megaselia serrata female, details of abdomen, tergites 7-10. 


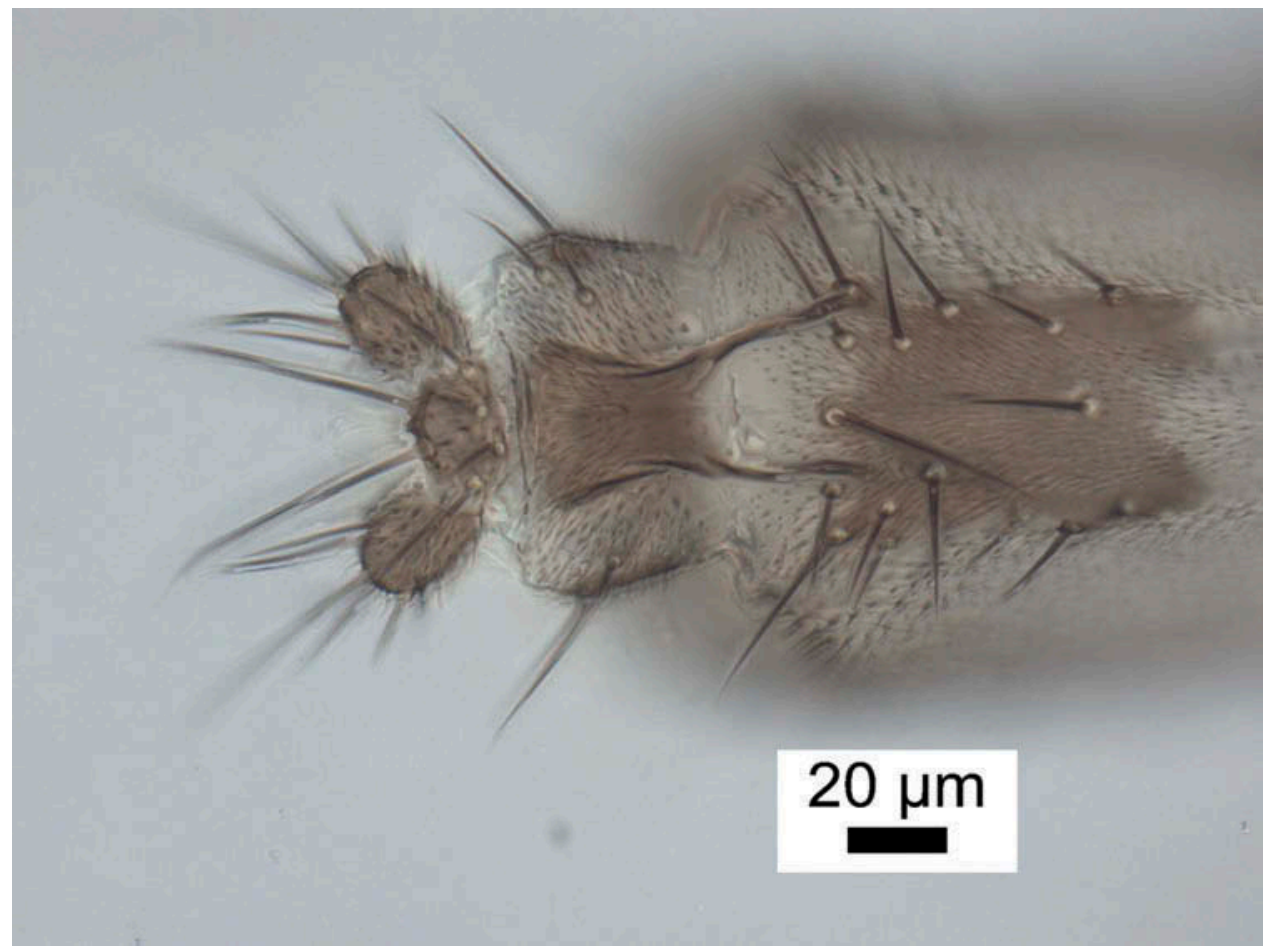

Figure 11. Megaselia serrata female, details of abdomen, terminal segments from above.

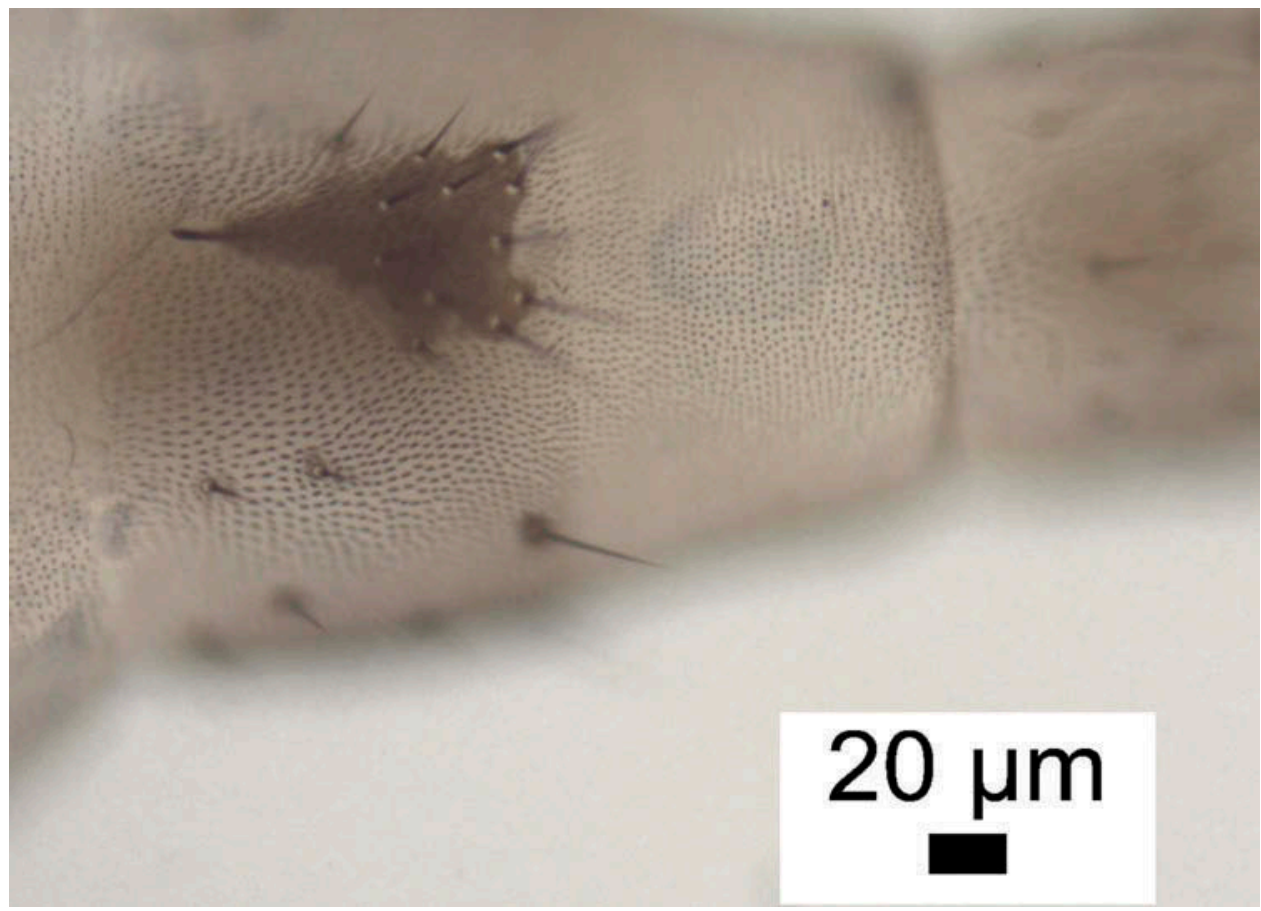

Figure 12. Megaselia serrata female, details of abdomen, sternite 7. 


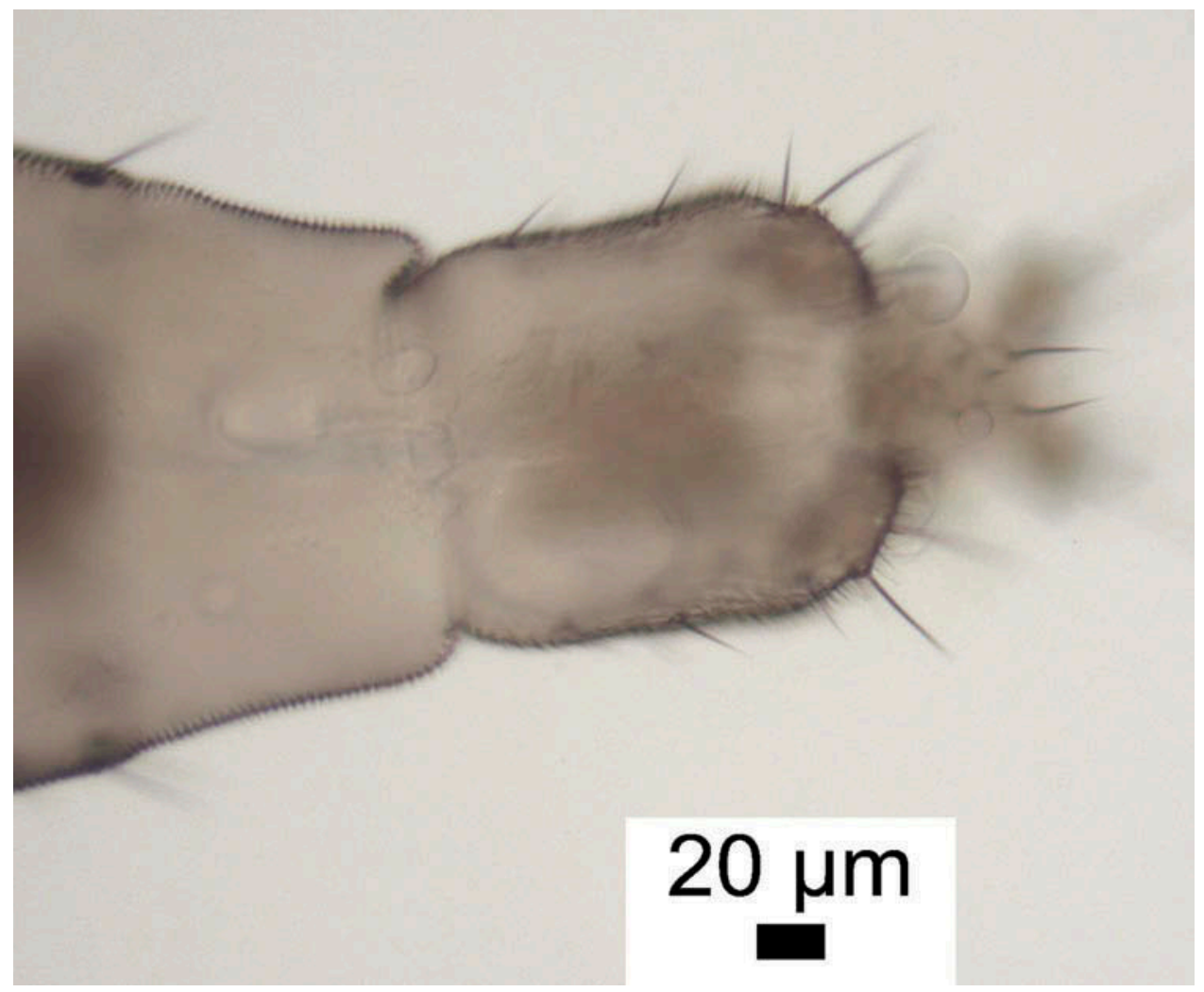

Figure 13. Megaselia serrata female, details of abdomen, lobes at rear of sternum 8 .

the hairs are subequal to the anteroventral hairs of the distal half. The dorsal hair palisade of mid tibia, as in male, extends about two thirds of length. Wing as male except 1.4-1.5 mm long. Costal index 0.40. Costal ratios 4.4:1.7:1. Costal cilia (of section 3) $0.07 \mathrm{~mm}$ long. Vein Sc not reaching vein 1 and with no hair at base of vein 3. With two unequal axillary bristles, the outer being longer than the costal cilia. Otherwise wing and haltere as male.

\section{Megaselia speiseri Schmitz}

(Figures 17-21)

Megaselia speiseri Schmitz 1929, p. 124 (male)

The male of this species is covered by the key to British species (Disney 1989). In the keys to the Palaearctic species, it is keyed out in Abteilung V (Schmitz and Delage 1974) and described in Schmitz and Delage (1981). However, the costal index varies across the division between those species with a costal index less than 0.44 (Abteilung V) and those whose costal index is 0.44 or more. Specimens with the longer costal index fall within Abteilung IV, Erste Reihe, whose species were keyed by Schmitz (1958). M. speiseri will run to couplet 15 in this key. The males of the species of this couplet, along with 


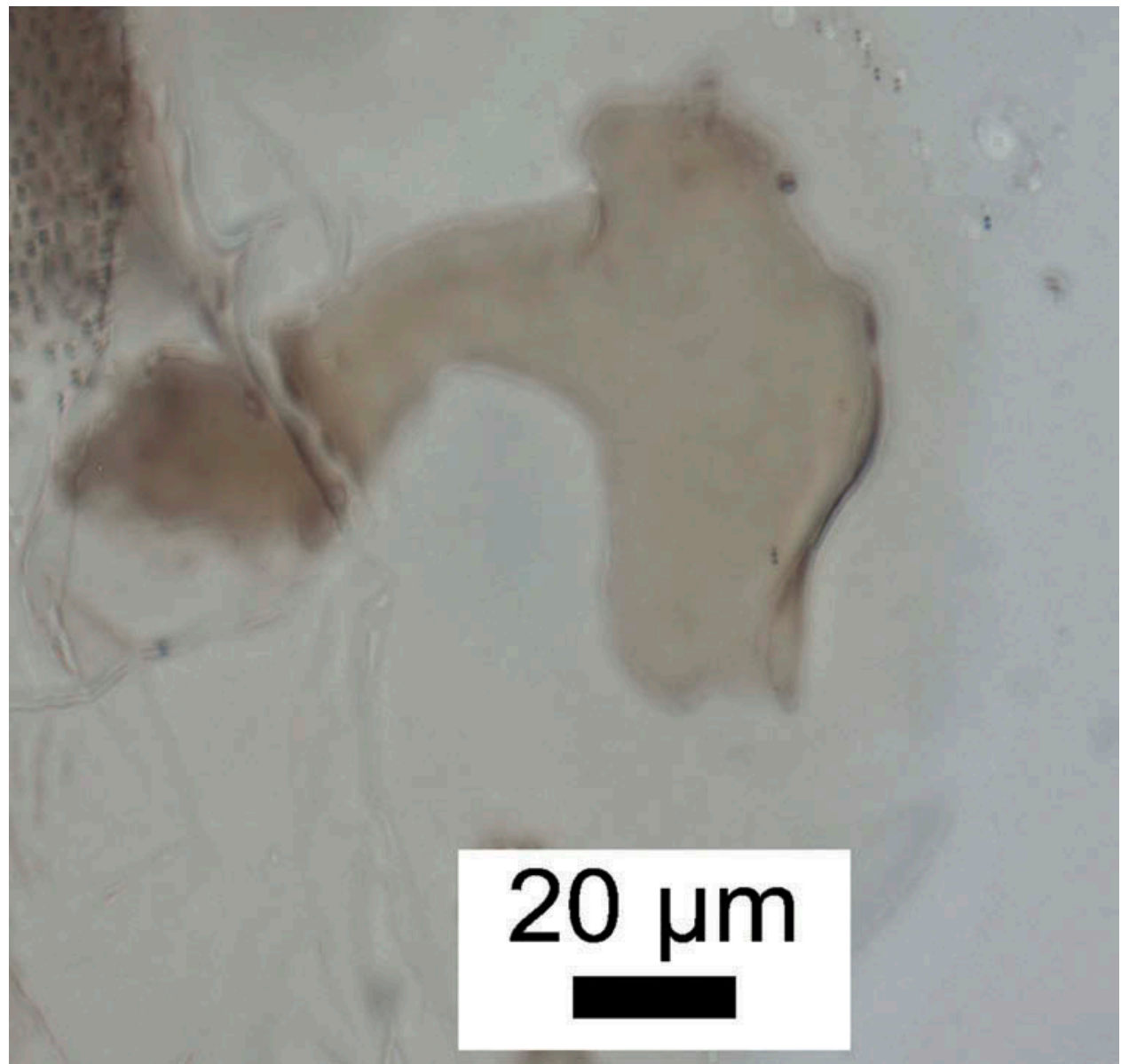

Figure 14. Megaselia serrata female, details of abdomen, furca.

others, are covered by Disney (1989). Hitherto the female of this species has remained unknown. It is described below.

\section{Female}

Head similar to male but labrum (Figure 17) about 1.5 times wider than diameter of postpedicel. Labella paler, with submarginal pale greyish bands above and only about a dozen, widely spaced, bristles reduced to small spinules below and at tips. Otherwise head similar to male. Thorax as in the male in that it has three notopleural bristles, 0-9 (mean: 5) hairs on mesopleuron and the scutellum with an anterior pair of hairs (about as strong as those in middle of scutum) and a posterior pair of bristles. Abdominal tergites brown. T3-T6 as Figure 18. Terminal segments as in Figure 19. Venter grey, and typically with hairs below segments 3-6, but sometimes none on 3, Sternite 7 and lobes at rear of sternum 8 as Figure 20. Cerci brown and at most 1.5 times as long as broad. Furca not evident. Dufour's crop mechanism as in Figure 21. Legs similar to 


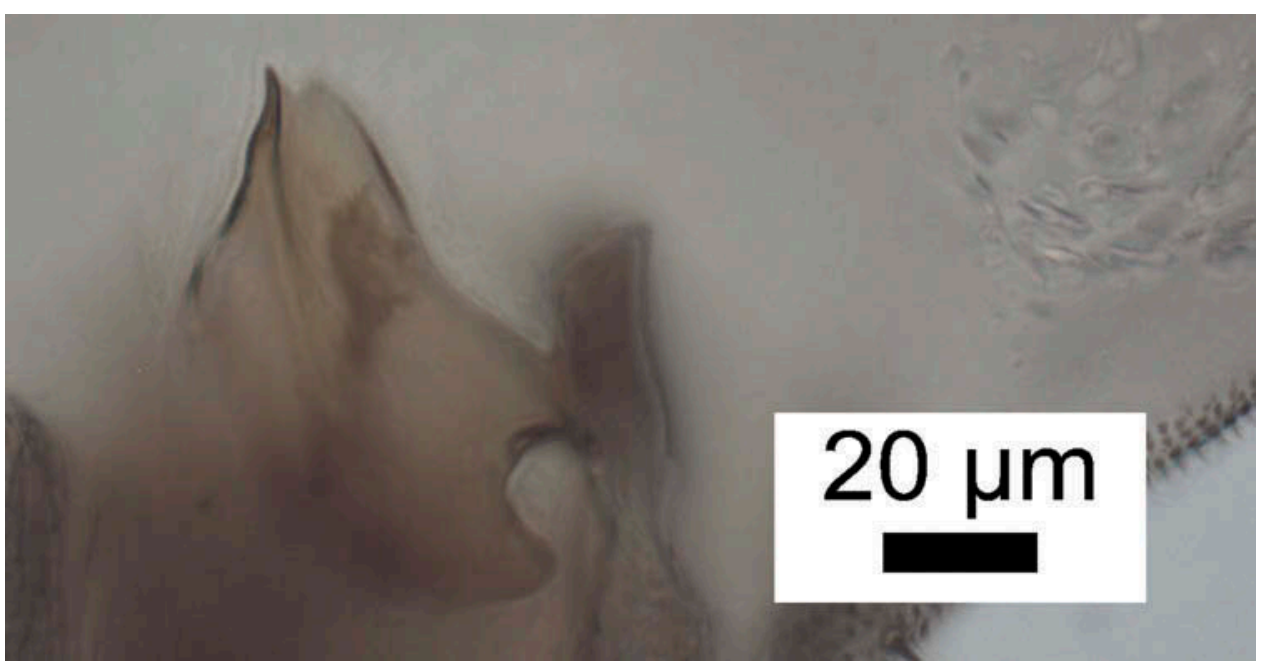

Figure 15. Megaselia serrata female, details of abdomen, furca from a second specimen.

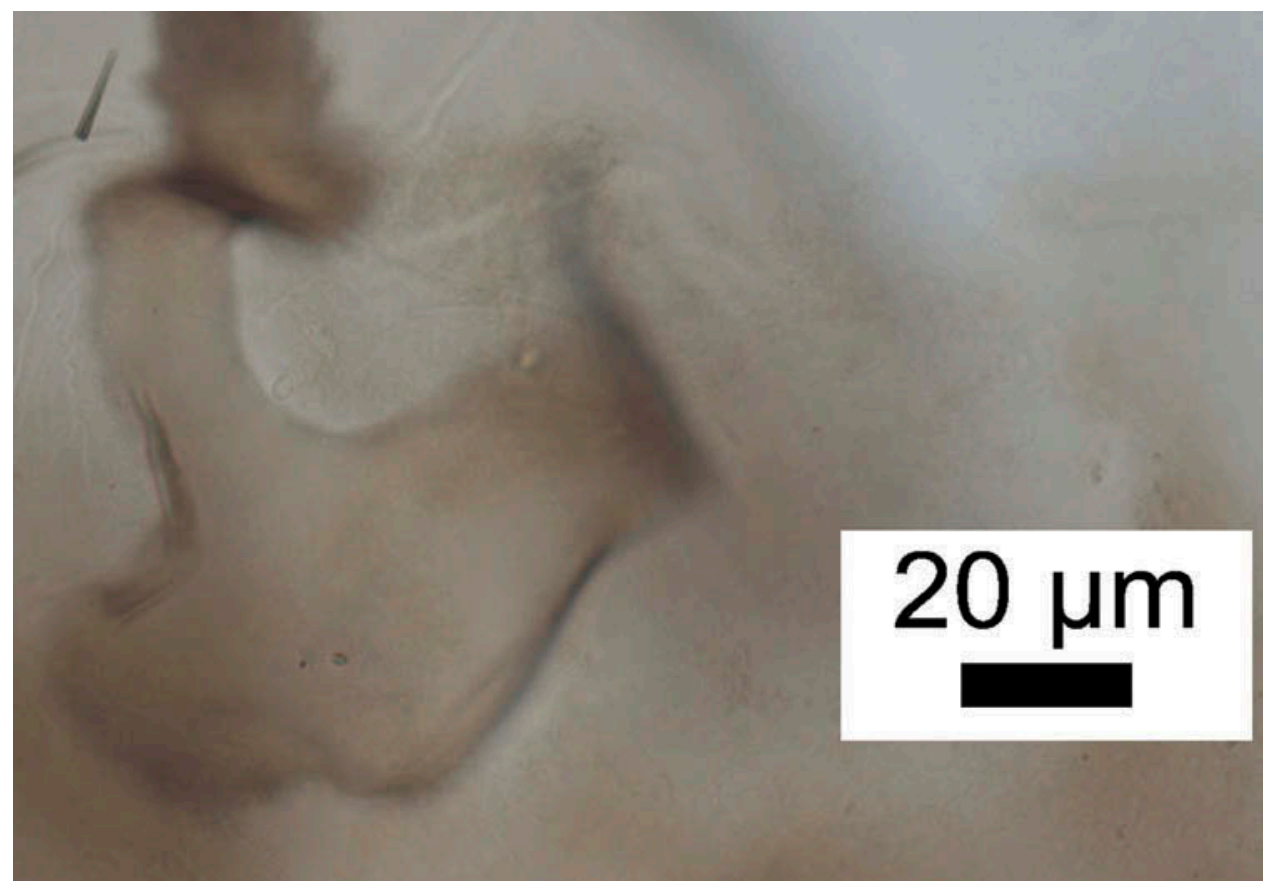

Figure 16. Megaselia serrata female, details of abdomen, furca from a third specimen.

male. Wing as in male except 1.3-1.6 mm long. Costal index 0.44-0.46. Costal ratios 2.5-4.2:1.1-1.5:1. Costal cilia $0.06-00.09 \mathrm{~mm}$ long. With two to three axillary bristles, the outermost being longer than the costal cilia. Otherwise it and haltere as male. 


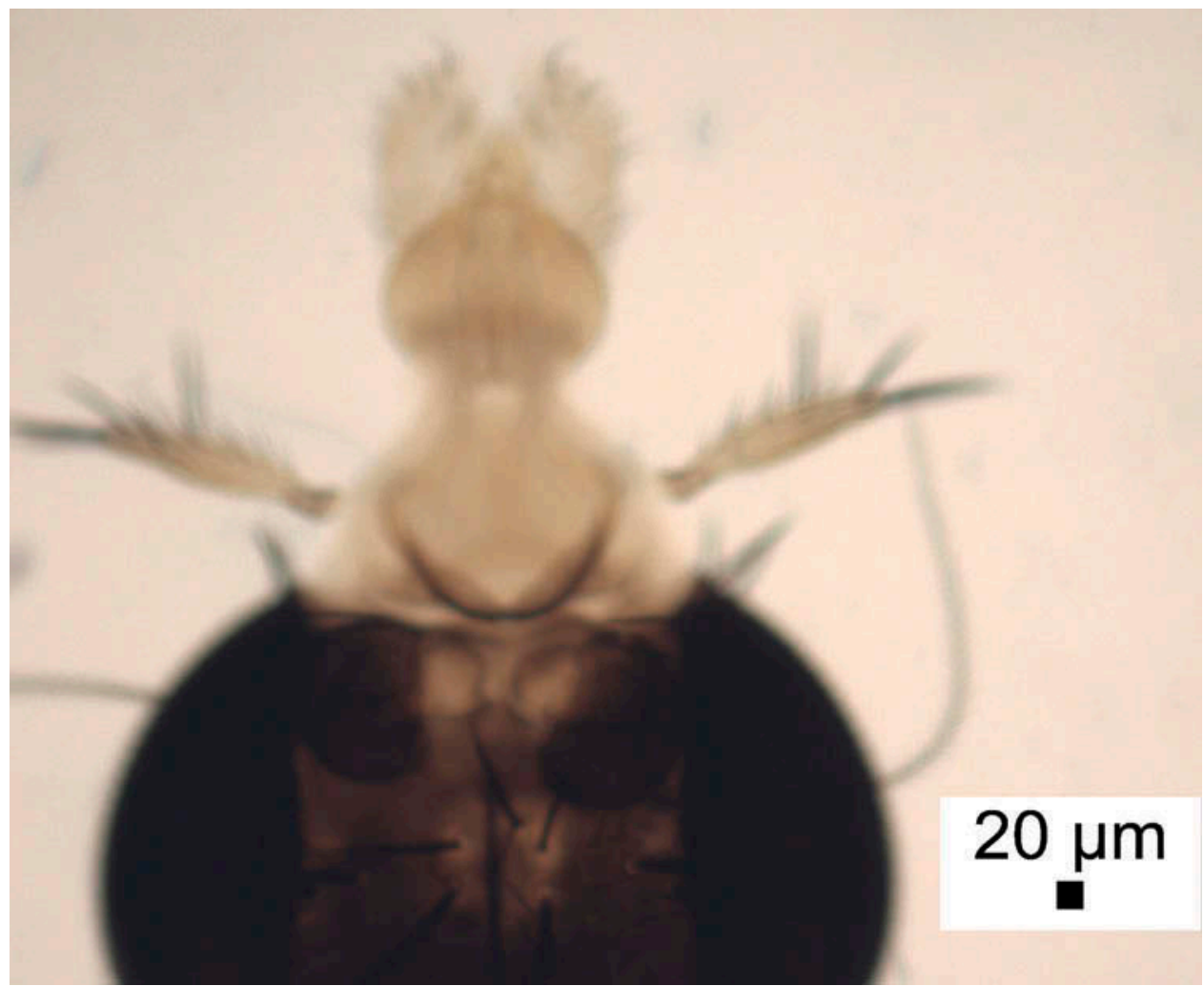

Figure 17. Megaselia speiseri female, proboscis and palps.

\section{Comment}

Variation in the number of the relatively few hairs on the mesopleuron includes a single female with a bare mesopleuron. A male with such a bare mesopleuron will fail to key out in the key to the males recorded from the British Isles (Disney 1989), or else its hypoppygium (loc. cit. fig. 318) obviously differs from those it may run to in the key, especially in having more than nine hairs on each cercus.

\section{Megaselia velutinicavus Disney, $\mathrm{sp} . \mathrm{n}$.}

(Figures 22A-D)

\section{Male}

Frons brown, clearly broader than long, with 60-62 hairs and dense but very fine microtrichia. SAs almost equal. The antials lower on frons than the anterolaterals but higher than the upper SAs, and about 2.5 times as far from the upper SAs as either is from an anterolateral bristle. Pre-ocellars a little farther apart than either is from a mediolateral bristle, which is a little higher on frons. Cheek with five bristles and jowl with two. The subglobose postpedicels brown and without SPS vesicles. Palps dusky 


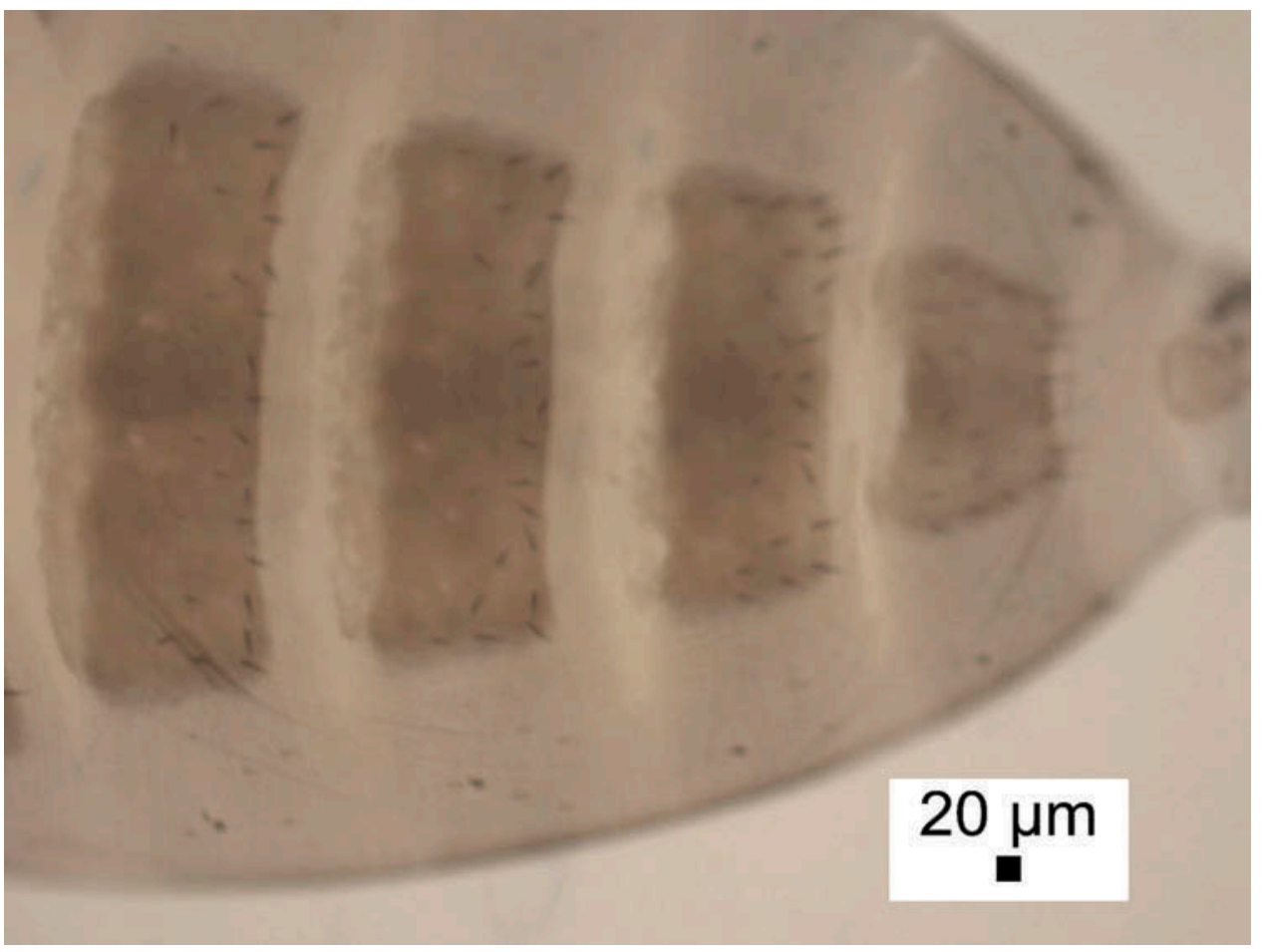

Figure 18. Megaselia speiseri female. details of abdomen, tergites 3-6.

yellow, at most a third as broad as postpedicel but about 1.3 times as long as breadth of latter, with four bristles and five hairs. Labrum pale yellowish grey and about half as wide as a postpedicel. Labella with combined width 1.5-1.6 times as broad as a postpedicel, paler than palps and the dorsolateral bands are only weakly pigmented, and with only six to eight short spinules at tip. Thorax brown. Three notopleural bristles and no cleft in front of these. Mesopleuron with six hairs. Scutellum with an anterior pair of hairs (about as strong as those in the middle of the scutum) and a posterior pair of bristles. Abdominal tergites brown with hairs longest at hind margins, especially on T6. Venter grey, and with hairs on segments 3-6. Hypopygium brown, with a grey anal tube, and as in Figures 22A and 22B. Legs brown. Fore tarsus with posterodorsal hair palisade on segments $1-4$, and 5 about as long as but broader than 4. Dorsal hair palisade of mid tibia extends almost half its length. Hairs below basal half of hind femur shorter than those of anteroventral row of outer half. Hind tibia with 24-26 differentiated posterodorsal hairs and spinules of apical combs simple. Hind basitarsus with an elongated, internal hairy cavity (Figures 22C-D). Wings $1.7 \mathrm{~mm}$ long. Costal index 0.40. Costal ratios 3.7:1.0:1. Costal cilia (of section 3) $0.17-0.18 \mathrm{~mm}$ long. No hair at base of vein 3 . With unequal axillary bristles, the outer being shorter than costal cilia. Sc not reaching R1. Thick veins light brown, thin veins 4-6 a little darker and 7 pale. Membrane tinged grey (evident to naked eye when viewed against a white background). Haltere brown. 


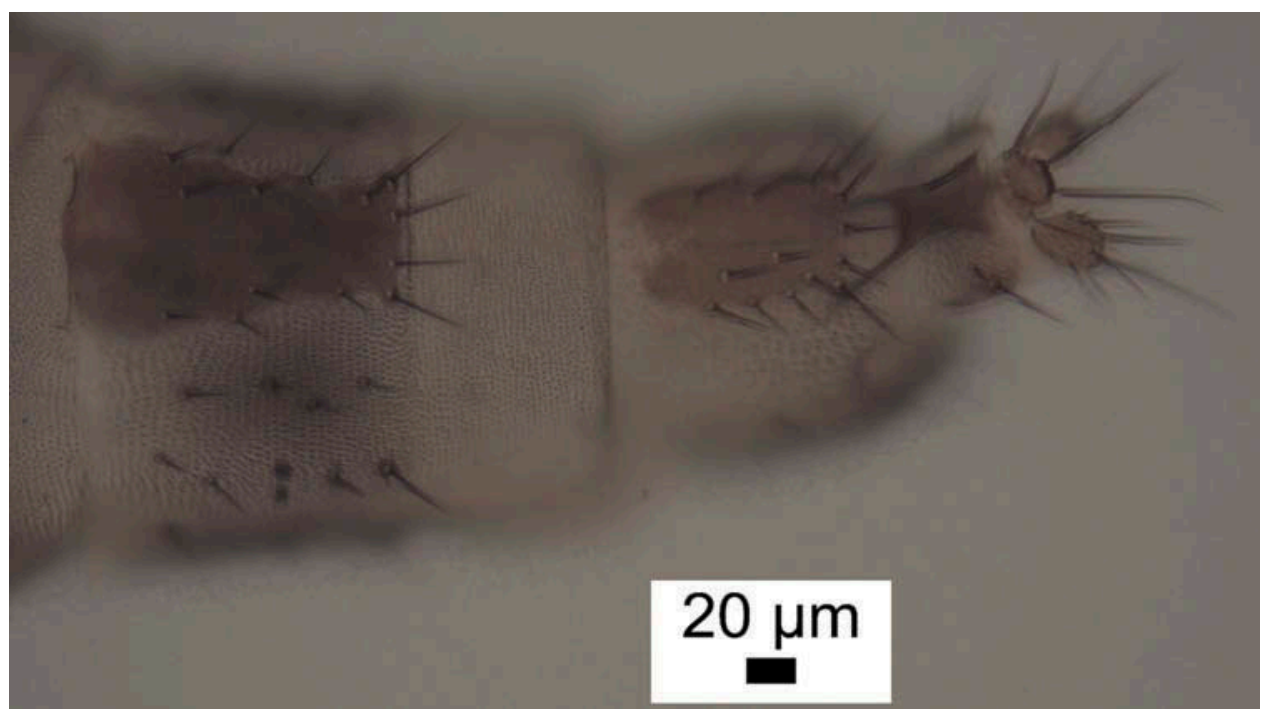

Figure 19. Megaselia speiseri female, terminal segments and cerci.

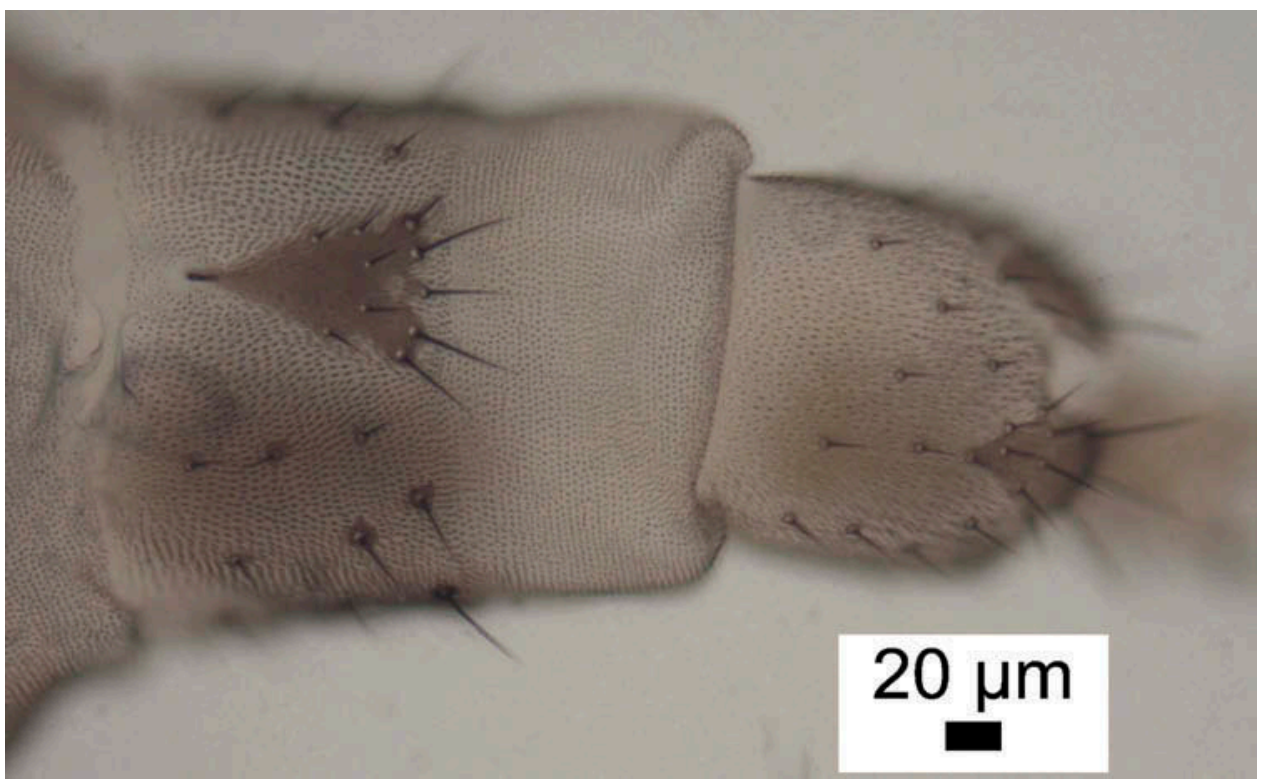

Figure 20. Megaselia speiseri female, sternite 7.

Holotype: male, England, Essex, Hainault Forest, (grid ref. TQ4894), crown of hornbeam (Carpinus betulus), 22.v-11.vi.2012, A. R-S, (UCMZ, 20-176).

\section{Etymology}

The name refers to the hair-lined cavity of the hind basitarsus. 


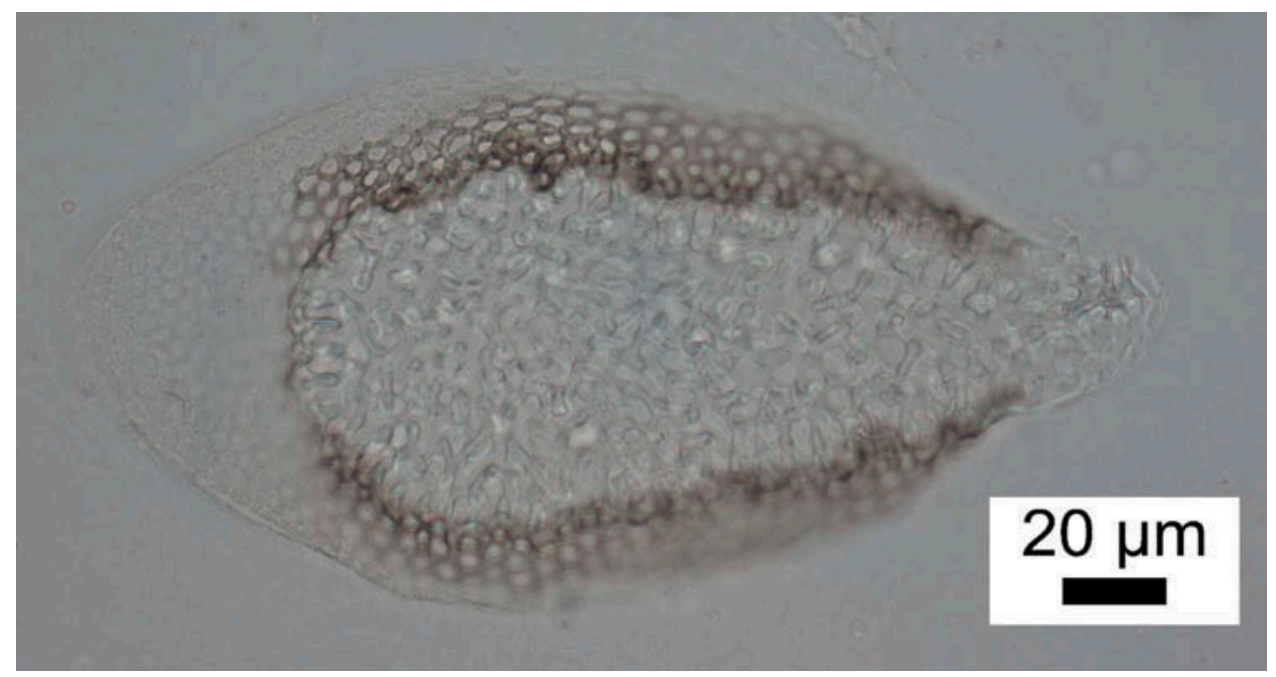

Figure 21. Megaselia speiseri female, Dufour's crop mechanism (anterior end to right).

\section{Recognition}

In the keys to British species (Disney 1989) the males run to couplets 130 and 131. This M. pusilla (Meigen) species complex has since been added to (Disney 2011). M. velutinicavus is immediately distinguished from the rest of this complex by the internal hairy cavity of the hind basitarsus (Figure 22D), apart from the hypopygium (Figures 22A-B).

\section{Megaselia D\&R-S sp. A}

(Figures 23-24)

This is probably a new species. However, the females of many species of Megaselia are unknown, are inadequately described or else have been incorrectly assigned to a species on the basis of co-occurrence at a locality on the same date.

The single specimen is a little damaged and with a quantity of debris adhering.

\section{Female}

Frons brown, clearly broader than long, with 40-44 hairs and dense but very fine microtrichia. SAs unequal, the lower pair at most two thirds as long as the upper pair. The antials about the same level on the frons as anterolaterals and upper SAs, and almost 3 times as far from upper SAs as from an anterolateral bristle. Pre-ocellars and mediolateral bristles almost equally spaced and at same level on frons. Cheek with three to five bristles and jowl with three that are longer. The subglobose postpedicels dusky yellow, without SPS vesicles. Palps whitish-grey, at most half as broad as postpedicel but about 1.8 times as long as breadth of latter, with five bristles and 10-13 hairs. Labrum pale yellow and about as wide as a postpedicel. Labella paler and their combined width about 1.7 times that of a postpedicel and with fewer than a dozen short spinules below each. Thorax mainly yellow above and brown on sides. Three notopleural bristles and no cleft in front of these. Mesopleuron bare. Scutellum with an anterior pair of hairs (about as 

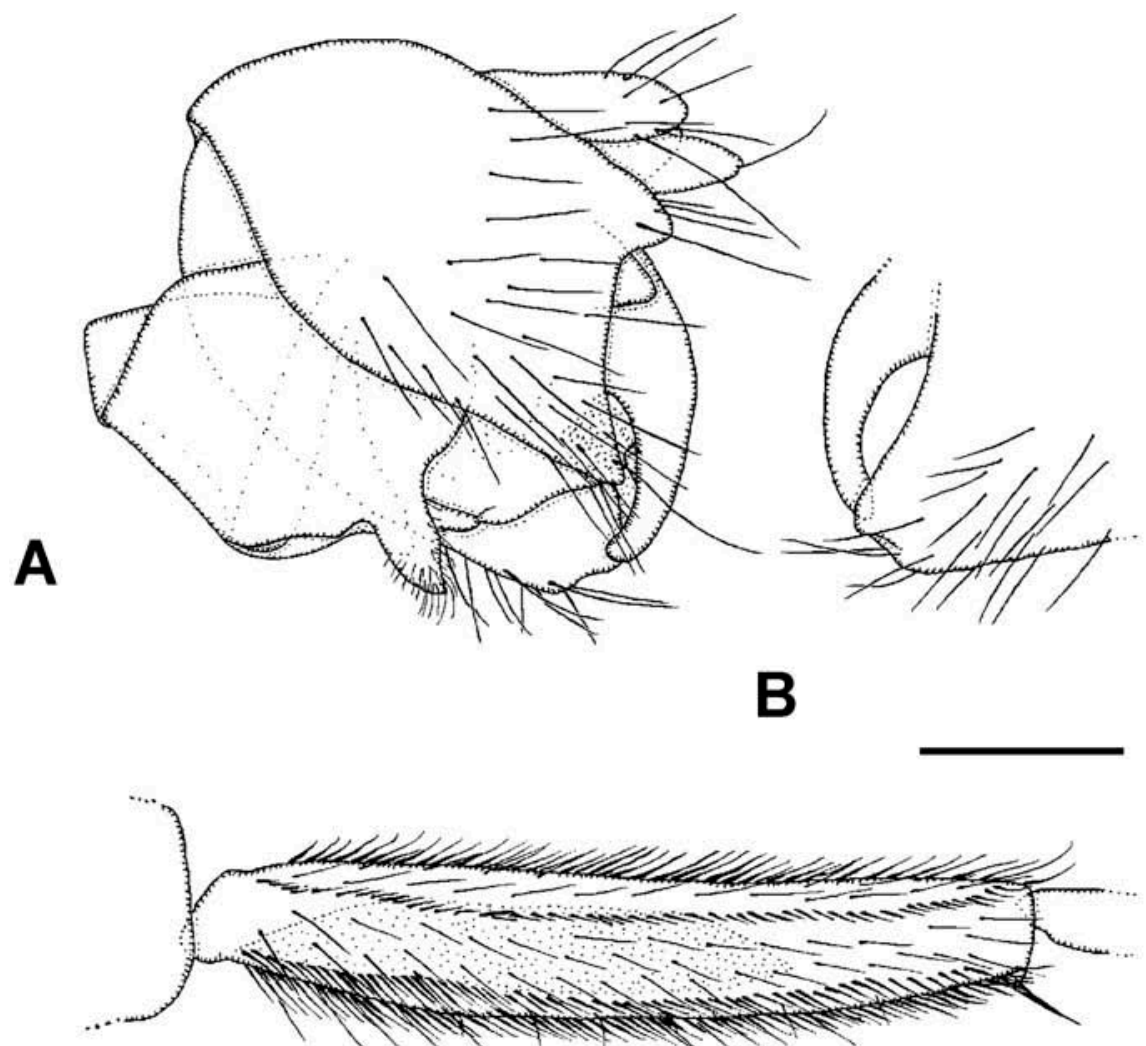

C

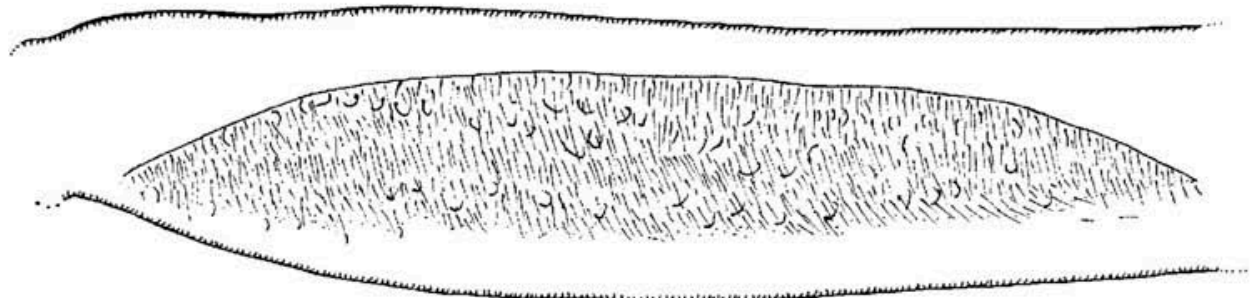

D

Figure 22. Megaselia veluitinicavus male. (A) Left face of hypopygium; (B) tips of right paraphysis and posteroventral region of epandrium; (C) anterior face of hind basitarsus; (D) the internal hairy cavity of the hind basitarsus (anterior focal plane). Scale bars: $0.1 \mathrm{~mm}$.

large as those in middle of scutum) and a posterior pair of bristles. Abdominal tergites 15 brown, T6 and T7 very faintly tinged brown and T8 devoid of pigment (Figure 23). Venter light grey, and with hairs on segments 3-6. Sternite 7 represented by hairs only. Posterolateral lobes at rear of sternum 8 short. Cerci pale whitish-grey and about 2.7 


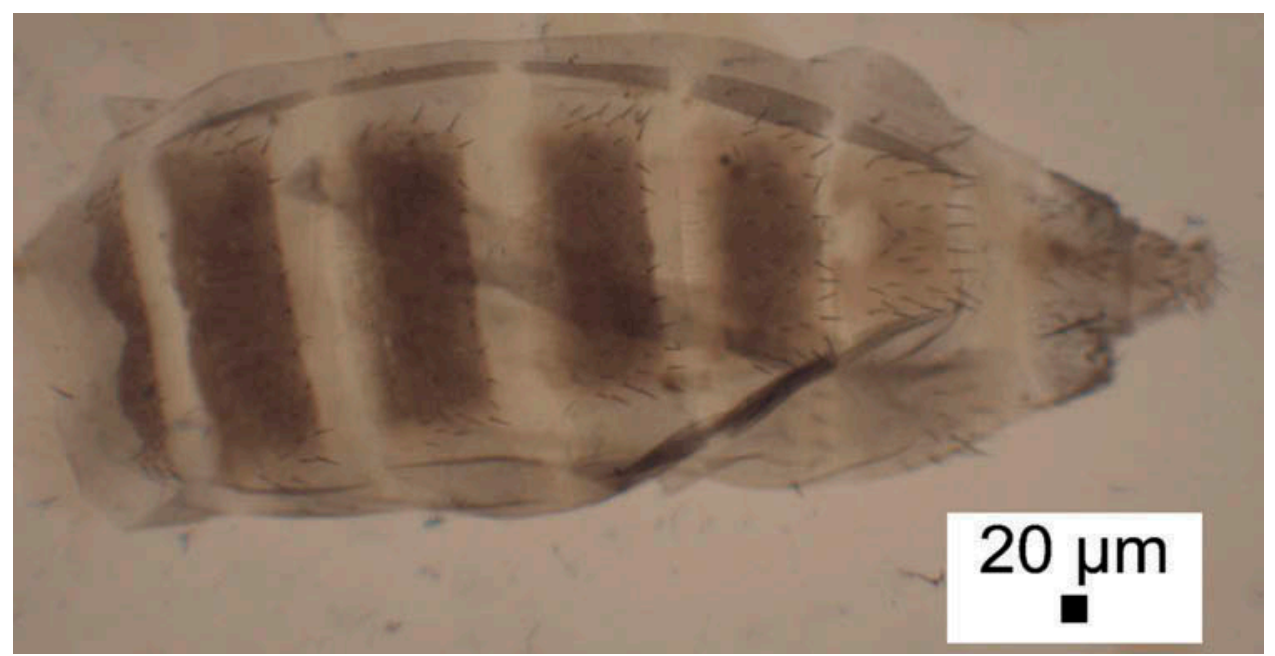

Figure 23. Megaselia D\&R-S sp. A, female, dorsal face of abdomen.

times as long as broad. Furca brownish grey and as in Figure 24. Dufour's crop mechanism not apparent. Legs yellow apart from brown patch on mid coxa and tip of hind femur. Fore tarsus with posterodorsal hair palisade on segments $1-4$, and 5 a little shorter than 4. Dorsal hair palisade of mid tibia extends about 0.7 times its length. Hairs below basal half of hind femur longer than those of anteroventral row of outer half. Hind tibia with at least a dozen differentiated posterodorsal hairs, and spinules of apical combs simple. Wings 1.8-1.9 mm long. Costal index 0.49-0.50. Costal ratios 4.4:2.8:1. Costal cilia (of section 3) $0.09-0.10 \mathrm{~mm}$ long. Hair at base of vein 3 minute. With three axillary bristles, the outer being longer than costal cilia. Sc not reaching R1. Thick veins light brown, thin veins 4-6 a little darker and 7 pale. Membrane tinged grey (just evident to naked eye when viewed against a white background). Haltere knob pale dusky yellow.

\section{Material}

Voucher female, Essex, Hatfield Forest (grid ref. TL5319), crown of ancient pollarded hornbeam (Carpinus betulus), 22.v-15.vi.2012 (UCMZ, 20-179)

Revised couplets 79-81 of the keys to the males of the British species of Megaselia (Disney 1989).

The following three species recorded from mainland Europe are also included. M. pedatella (Schmitz), whose recognition was clarified by Disney (2003), M. altezza Brenner (2006) and M. meridiana Brenner (2004).

79 Haltere brown

- Knob of haltere yellow. (Hypopygium as in Figure 25) Body length less than $2 \mathrm{~mm}$ ) pedatella (Schmitz)

80 Anal tube clearly longer than midline length of dorsal face of epandrium 81

- Anal tube subequal to or shorter than dorsal face of epandrium 


\section{$20 \mu \mathrm{m}$}

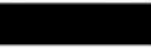

Figure 24. Megaselia D\&R-S sp. A, female, furca.

81 Hypopygium as in Figures 7A-B, each cercus having fewer than 10 hairs. The costal cilia (of section 3) less than $0.1 \mathrm{~mm}$ long. With only two bristles on axillary ridge russellsmithi Disney

- Hypopygium as in Figures 4A-B and 5B-C, each cercus having more than 10 hairs. The costal cilia more than $0.1 \mathrm{~mm}$ long. With three to four bristles on axillary ridge henrydisneyi Durska

82 Left half of hypandrium lacks a lobe projecting rearwards 83

- Left lobe of hypandrium present 84

83 Hypopygium as in fig. 314 (in Disney 1989), each cercus having more than 10 hairs. Mid and front tibiae yellowish hortensis (Wood)

- Hypopygium as in fig. 316 (in Disney 1989), each cercus having less than 10 hairs. All femora dark brown alticolella (Wood) 


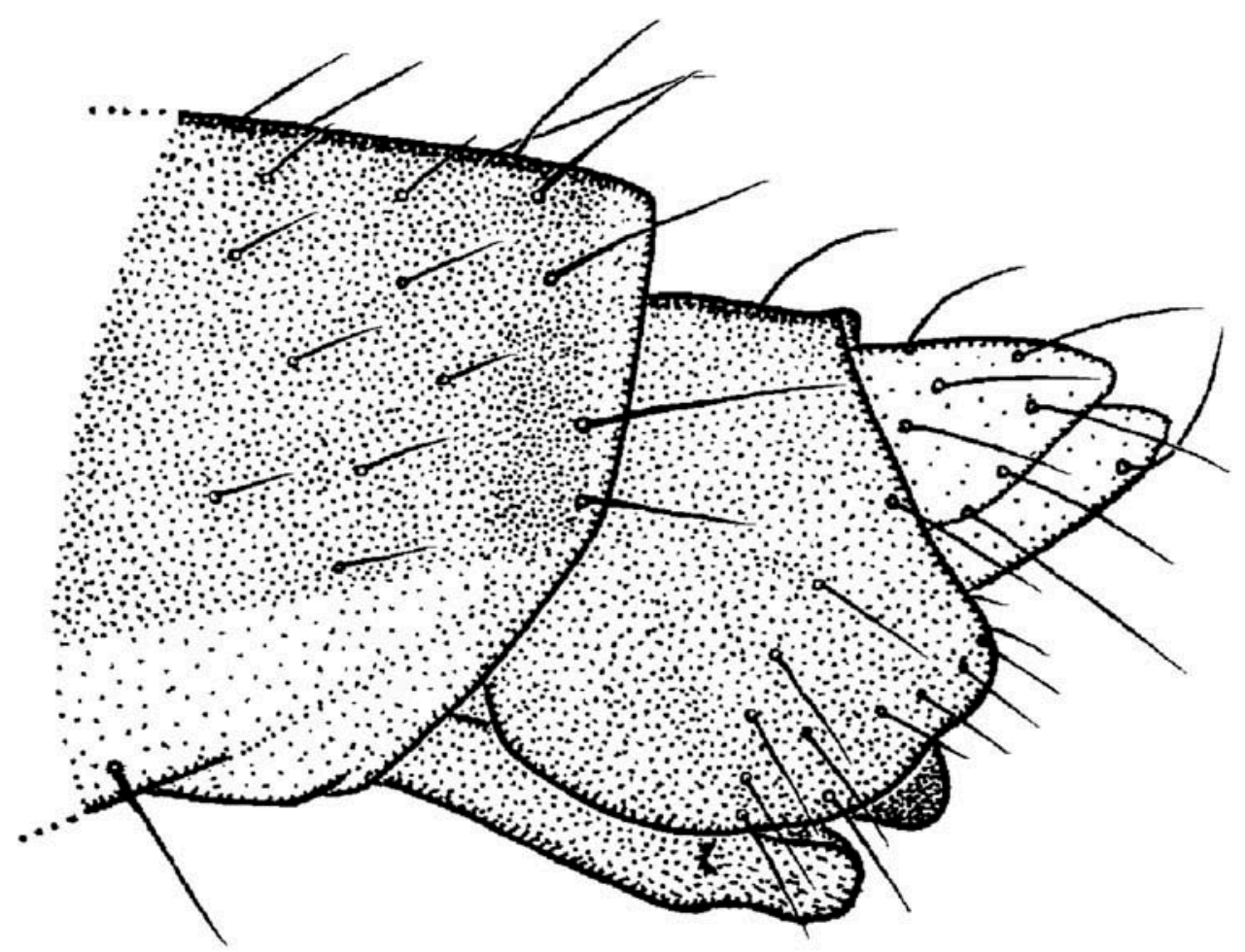

Figure 25. Megaselia pedatella male, left face of hypopygium. Scale bar: $0.1 \mathrm{~mm}$.

84 Fifth segment of front tarsus clearly longer than fourth and all segments with a posterodorsal hair palisade (e.g. Figure 1A)

- Fifth segment of front tarsus about as long as fourth and lacking a posterodorsal hair palisade. (Hypopygium as in figs. 2-3 in Brenner 2006.) Wing length less than $1 / 5$ $\mathrm{mm}$. Costal cilia of section 3 less than $0.1 \mathrm{~mm}$ long. Hairs below basal half of hind femur shorter than those of anteroventral row of outer half) ...... meridiana Brenner

85 Palps yellow. Axillary ridge of wing with two to three bristles 86

- Palps brown. Axillary ridge of wing with four to five bristles. (Hypopygium as in fig. 1 in Brenner, 2004) altezza Brenner

86 Epandrium hairs about as robust as those at rear of abdominal tergite 6 (Figure 2). Left lobe of hypandrium with microtrichia (Figure 3)

crassipes (Wood)

- The hairs towards lower edges of epandrium thicker, bristle-like and clearly more robust than those at rear of T6. Left lobe of hypandrium bare but with fine irregular fine fluting. (Figure 6) return to couplet 81

The precise numbers of each species trapped are not recorded, not least because there was a high frequency of teneral specimens which are frequently not readily identified 
without the use of molecular barcodes. The numbers recorded below are for the minimum number of samples in which a species was obtained. The returns are for more than 30 traps. However, the catches were typically for several traps combined (ranging from 1 to 30 traps, but most frequently for five). In some cases, two or more samples were amalgamated. Furthermore, the duration for which a trap was set ranged from 24 to 63 days. These limitations preclude the use of statistical analysis, but the non-equivalent samples below do allow an indication of the relative abundances of the species.

The full list of Phoridae recorded from pitfall traps set in the crowns of ancient pollards in the South of England is as follows, with the localities abbreviated thus: $\mathrm{BB}=$ Burnham Beeches, Berks; $\mathrm{BW}=$ Bockhanger Wood, Merton Hatch, Kent; $\mathrm{HF}=$ Hainault Forest, Essex; HT = Hatfield Forest, Essex; WGP = Windsor Great Park, Berks; WW = Wytham Woods, Oxford; and the tree species thus: $\mathrm{Cb}=$ hornbeams (Carpinus betulus), Fs = beech (Fagus sylvatica), $Q=$ oaks (Quercus spp); samples from limes (Tilia sp.) were mixed with those from beech, $X=$ mixed samples from more one tree species. These codes are followed by the number of samples in each case.

The female attributed to Conicera tarsalis does not run to any of the species included in Buck's (2001a) incomplete key to the females of the European species of this genus.

The known larval habits are from the review in Disney (1994), except where indicated otherwise.

Anevrina thoracica (Meigen)Bb-X-2, HF-Cb-4, HT-Cb-1 = seven samples. Larvae reported from dead snails.

A. unispinosa (Zetterstedt)BB- X1, HT-Cb-1 = two samples. Larvae reported from invertebrate and vertebrate carrion.

Conicera floricola SchmitzBB-X2 = two samples.

C. tibialis SchmitzBW-Cb-1 = one sample. The larvae feed on vertebrate carrion (especially when buried in the soil).

Conicera sp. a female, possibly $C$. tarsalis Schmitz, whose female has not been adequately characterised $\mathrm{BW}-\mathrm{Cb}-1=$ one sample.

Diplonevra pilosella (Schmitz)BW-Cb-1 = one sample. It has been reared from a wounded earthworm (Lumbricidae).

Gymnophora quartomollis SchmitzWGP-Q1 = one sample.

Megaselia aculeata (Schmitz)BB-X1, HT-Cb2 = three samples.

M. altifrons (Wood)BB-X1, BW-Cb5, HF-Cb5, WGP-Q1, WW-Fs1 = 13 samples.

M. angusta (Wood)BW-Cb4, HF-Cb4, HT-Cb3 = 11 samples. It has been reared from invertebrate and vertebrate carrion, decaying fungi and plant material.

M. basispinata (Lundbeck)BB-X1, BW-Cb2, HF-Cb4, Ht-Cb1, WGP-Q2 $=10$ samples.

M. breviterga (Lundbeck)BW-Cb1, HF-Cp1, WW-Q1 = three samples.

M. ciliata (Zetterstedt) HF - Cb - $2=$ two samples. The larvae are predators of slug eggs (Arion sp. and Deroceras sp.).

M. cinerea Schmitz BB-X-2, HT-Cb-1, WGP-Q-4 = seven samples.

M. diversa (Wood)BW-Cb4, HF-Cb2, HT-Cb - 1, WGP-Q - 1 = eight samples.

M. errata (Wood)BB-X - 3, WW-Fs1 = four samples. Buck (1997b, 2001b) reported this species breeding in baits of dead snails.

M. funesta DisneyWGP-Q1 = one sample. 
M. fungivora (Wood)BB-X1 = one sample.

M. giraudii (Egger)BB-X2, BW-Cb3, HF-Cb3, HT-Cb3, WGP-Q7 = 18 samples. SchmitzBB-X2, HT-Cb - 1, WGP-Q - 4 = seven samples. The larvae feed on a wide range of invertebrate and vertebrate carrion and other decaying matter.

$M$. henrydisneyi DurskaBB-X - 2, BW-Cb - 1, HT- Cb2, W-GPQ2 = seven samples.

$M$. hirtiventris (Wood)HT $-\mathrm{Cb} 1=$ one sample. The larvae develop in fungi. M. ignobilis (Schmitz)BW -Cb 1, HF -Cb 1, HT-Cb3 = five samples.

M. insons (Lundbeck)BB -X1, WGP - Q2 = three samples.

$M$. involuta (Wood)WGP-Q2 = two samples.

M. latipalpis (Schmitz)WGP-Fs1 = one sample.

M. longicostalis (Wood)BB-X - $1 \mathrm{BW}-\mathrm{Cb}-3, \mathrm{HF}-\mathrm{Cb} 4$, WGP-Q1 = nine samples. The larvae feed on a wide range of invertebrate and vertebrate carrion and other decaying matter.

M. longifurca (Lundbeck)HF-Cb1 = one sample. The larvae prey on the eggs of spiders.

M. melanocephala (von Roser)BW-Cb1 = one sample. The larvae prey upon the eggs of the cave-dwelling spider. Meta menardi (Tetragnathidae),

M. nigriceps (Loew)BW- Cb4, HF-Cb3, HT-Cb1, WGP-Q1 = nine samples. It has been reared from a rotten willow $\log$ and dead insects.

M. pleuralis (Wood)BB-X2, BW-Cb 3, HF-Cb2, HT -Cb4 = 11 samples. It has been reared from bird and mammal dung and other decaying organic materials.

M. pseudogiraudii (Schmitz)BB-X1, BW-Cb6, HF-Cb7, HT-Cb3, WGP-Q3, WWFs2 $=22$ samples.

M. pusilla (Meigen)HF-Cb1, HT-Cb1, WGP-Q - $1=$ three samples.

M. pygmaea (Zetterstedt)WW- Fs1 = one sample.

$M$. rubescens (Wood)HT $-\mathrm{Cb} 2$, WGP-Q $1=$ three samples. It has been reared from a range of fungus sporophores.

M. ruficornis (Meigen)BW-Cb5, HF-Cb3, WGP-Q - 1 = nine samples. It has been reared from dung and vertebrate and invertebrate carrion.

M. rufipes (Meigen)BB-X4, BW-Cb6, HF-Cb - 6, HT-Cb- 4, WGP- Q $10=30$ samples. The larvae exploit a wide range of decaying organic materials.

$M$. rupestris $\mathrm{SchmitzHF}-\mathrm{Cb} 1=$ one sample.

$M$. russellsmithi $\mathrm{n}$. sp.WGP-Q2 $=$ one sample.

$M$. serrata (Wood)WGP- Q2 = two samples.

M. shawi DisneyHF-Cb - $1=$ one sample. It has been reared from the sporophore of a fungus (Ševčík 2010).

M. speiseri SchmitzWGP -Q3 = three samples.

M. spinicincta (Wood)BB $-\mathrm{X} 1=$ one sample. It has been reared from fungus sporophores.

M. subcarpalis (Lundbeck)BW- Cb1, WGP- Q2 = three samples.

M. sylvatica (Wood)BB- X2 = two samples. It has been reared from the sporophores of fungi.

M. tenebricola SchmitzHT-Cb1 = one sample.

$M$. velutinicavus $\mathrm{n}$. sp. $\mathrm{HF}-\mathrm{Cb} 1=$ one sample.

$M$. sp. (female) D\&R-S sp. AWW-Fs - $1=$ one sample. 


\section{Discussion}

With the unidentified females of some Megaselia species, about 50 species were obtained in this study. The number of new species and additions to the British List is, perhaps, surprising. However, the list of species recorded for a particular locality, district or country depends upon the amount of collecting effort, the range of collecting methods employed (e.g. Disney et al. 1982) and the elements of the habitat sampled. For example, Gymnophora healeyae Disney is so far only known from pitfall traps at several sites in upland England. Megaselia symondsi Disney (2002) was added when the canopy of an oak tree was sampled, and $M$. correlata (Schmitz), previously known from a single specimen from Germany, was subsequently reported to represent up to $10.9 \%$ of the Phoridae obtained from the canopies of oak trees (Quercus spp.) near Oxford, along with Obscuriphora sheppardi Disney, previously known from a single site in England, that represented about $2 \%$ of the phorids (Disney 1994). O. sheppardi was subsequently reported from the canopies of pine trees (Pinus sylvestris) in Poland (Durska 2001). New species and new records were added to the list of Phoridae recorded from France when those emerging from rot-holes in trees were sampled (Disney and Withers 2011). Thus, the novelties reported above represent a further case of the sampling of a previously neglected element of the habitat, producing novel additions to faunal lists.

\section{Acknowledgements}

RHLD is grateful to Dr. Thomas Pape (Natural History Museum of Denmark, Copenhagen), Dr. Ximo Mengual (Museum Koenig, Bonn) and Nigel Wyatt (Natural History Museum, London) for the loan of type material in their cares. His studies of Phoridae are currently supported by grants from the Balfour-Browne Trust Fund (University of Cambridge).

\section{References}

Borgmeier T. 1968. A catalogue of the Phoridae of the world (Diptera, Phoridae). Studia Entomologica, Petropolis. 11:1-367.

Brenner S. 2004. Five new Megaselia species and the hitherto undescribed male of $M$. norica Schmitz, 1929, from Austria (Diptera: Phoridae). Entomologist's Gazette. 55:127-140.

Brenner S. 2006. Some new species of Megaselia Rondani (Diptera: Phoridae) from Austria (Nord-Tirol) and Italy (Süd-Tirol). Entomologist's Gazette. 57:119-135.

Buck M. 1997. Untersuchungen zur ökologischen Einnischung saprophager Dipteren unter besonderers Berücksichtigung der Phoridae und Sphaeroceridae (Brachycera/ Cyclorrhapha) [Doctoral Thesis, Universität Ulm]. Göttingen: Cuvillier Verlag.

Buck M. 2001a. Identification of females of European Conicera Meigen, with a discussion of certain features of the reproductive anatomy of female Phoridae (Diptera). Mitteilungen aus dem Museum für Naturkunde, Berlin, Deutsche Entomologische Zeitschrift 48: 69-81.

Buck M. 2001b. Protogyny, protandry, and bimodal emergence patterns in necrophagous Diptera. The Canadian Entomologist. 133:521-531. doi:10.4039/Ent133521-4

Disney RHL. 1989. Scuttle Flies - Diptera Phoridae Genus Megaselia. Handbk Ident Br Insects. 10:1-155.

Disney RHL. 1994. Scuttle Flies: The Phoridae. London: Chapman \& Hall. xii + 467 pp. ISBN 0412562520 X. [Archived by Springer Book Archives - https://www.springer.com].

Disney RHL. 2001. The preservation of small Diptera. Entomol Mon Mag. 137:155-159.

Disney RHL. 2002. A new species of Megaselia (Rondani) from Hayley Wood, Cambridgeshire (Diptera: Phoridae). Entomol Rec. 114:189-191. 
Disney RHL. 2003. Revisionary notes on European Phoridae (Diptera). Bonner Zoologische Beiträge. 50:293-304.

Disney RHL. 2011. A further sibling species of Megaselia pusilla (Meigen) (Dipt., Phoridae). Entomol Mon Mag. 146:173-177.

Disney RHL, Durska E. 1998. A new genus and new species of Phoridae (Diptera) from Poland. Eur J. Entomol. 95:437-453.

Disney RHL, Durska E. 2011. Five new species and new records of Megaselia Rondani (Diptera: Phoridae) from Poland. Annales Zoologici (Warszawa). 61:527-534.

Disney RHL, Erzinclioglu YZ, Henshaw DJdeC, Howse D, Unwin DM, Withers P, Woods A. 1982. Collecting methods and the adequacy of attempted fauna surveys, with reference to the Diptera. Field Studies. 5:607-621.

Disney RHL, Withers P. 2011. Scuttle flies (Diptera, Phoridae) reared from tree rotholes in France, including three new species of Megaselia Rondani. Fragmenta Faunistica. 54:2941. doi:10.3161/00159301FF2011.54.1.029

Durska E. 2001. Secondary succession of scuttle fly communities (Diptera: Phoridae) in moist pine forest in Białowieża Forest. Fragmenta Faunistica. 44:79-128. doi:10.3161/ 00159301FF2001.44.1.079

Lundbeck W. 1920. New species of Aphiochaeta from Denmark. Videnskabelige Meddelelser fra Dansk naturhistorisk Forening i Kjøbenhavn. 71:1-34.

Lundbeck W. 1921. New species of Phoridae from Denmark, together with remarks on Aphiochaeta groenlandica Lundb. Videnskabelige Meddelelser fra Dansk naturhistorisk Forening i Kjøbenhavn. 72:129-143.

Lundbeck W. 1922. Diptera Danica Part VI Pipunculidae, Phoridae. London: Wesley.

Schmitz H. 1929. Neue Megaselia-Arten. II. Natuurhistorisch Maandblad. 18:124-127.

Schmitz H. 1948. Zweiter Beitrag zur Kenntnis der Phoriden Österreichs (Diptera). Annalen des Naturhistorischen Museums, Wien. 56:375-399.

Schmitz H. 1952. Über W. Lundbecks Sammlung und Beschreibung Dänischer Phoriden. Entomologiske Meddelelser. 26:350-379.

Schmitz H.1958. Phoridae. In: Lindner E, editor. Die Fliegen der palaearktischen Region 4(33) (Lieferung 202). Stuttgart: E. Schweizerbart'sche Verlagsbuchhandlung; p. 465-512.

Schmitz H, Beyer E. 1965. Phoridae. In: Lindner E editor. Die Fliegen der palaearktischen Region 4(33) (Lieferung 258, 260). Stuttgart: E. Schweizerbart'sche Verlagsbuchhandlung; p. 513-608.

Schmitz H, Delage A. 1974. Phoridae. In: Lindner E editor. Die Fliegen der palaearktischen Region 4 (33) (Lieferung 301). Stuttgart: E. Schweizerbart'sche Verlagsbuchhandlung; p. 638-664.

Schmitz H, Delage A. 1981. Phoridae. In: Lindner E editor. Die Fliegen der palaearktischen Region 4 (33) (Lieferung 325). Stuttgart: E. Schweizerbart'sche Verlagsbuchhandlung; p. 665-712.

Ševčík J. 2010. Czech and Slovak Diptera associated with fungi. Opava: Slezské zemské museum; 112 p. ISBN 978-80-86224-84-8.

Simon E. 1894. Histoire naturelle des araignées. Paris. 1:489-760.

Wood JH. 1909. On the British species of Phora. Part II contd. Entomol Mon Mag. 45:24-29, 59-63, 113-120, 143-149, 191-195, 240-244.

Wood JH. 1910. On the British species of Phora (contd). Entomol Mon Mag. 46:149-154, 195-202, 243-249. 